\title{
Review of Research Results for the Photocatalytic Oxidation of Hazardous Wastes in Air
}

Mark R. Nimlos, Edward J. Wolfrum, David A Gratson, Andrew S. Watt, and Craig Turchi

National Renewable Energy Laboratory 1617 Cole Boulevard Golden, Colorado 80401-3393

A national laboratory of the U.S. Department of Energy Managed by Midwest Research Institute for the Department of Energy under contract No. DE-AC36-83CH10093

Prepared under Subtask No. SI51.3050

January 1995 


\section{NOTICE}

This report was prepared as an account of work sponsored by an agency of the United States government. Neither the United States government nor any agency thereof, nor any of their employees, makes any warranty, express or implied, or assumes any legal liability or responsibility for the accuracy, completeness, or usefulness of any information, apparatus, product, or process disclosed, or represents that its use would not infringe privately owned rights. Reference herein to any specific commercial product, process, or service by trade name, trademark, manufacturer, or otherwise does not necessarily constitute or imply its endorsement, recommendation, or favoring by the United States government or any agency thereof. The views and opinions of authors expressed herein do not necessarily state or reflect those of the United States government or any agency thereof.

Available to DOE and DOE contractors from:

Office of Scientific and Technical Information (OSTI)

P.O. Box 62

Oak Ridge, TN 37831

Prices available by calling (615) 576-8401

Available to the public from:

National Technical Information Service (NTIS)

U.S. Department of Commerce

5285 Port Royal Road

Springfield, VA 22161

(703) $487-4650$ 


\section{Contents}

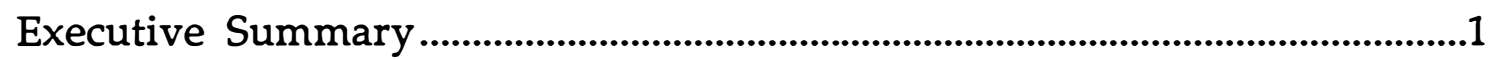

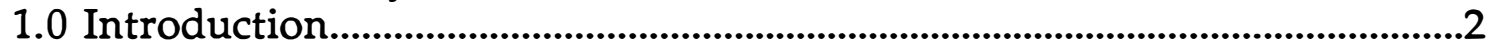

1.1 Potential for Gas-Phase Photocatalysis ..................................................

1.2 History of Gas-Phase Photocatalysis...............................................................

1.3 Early NREL Laboratory Studies.....................................................................

1.4 Format of Report.............................................................................................4

1.5 References for Chapter One.........................................................................4

2.0 Photocatalytic Oxidation of Trichloroethylene ....................................................6

2.1 Introduction ...............................................................................................6

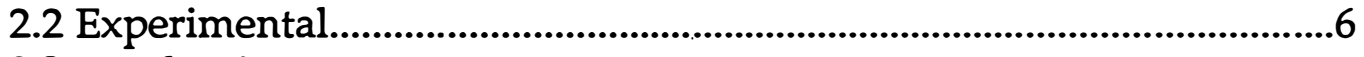

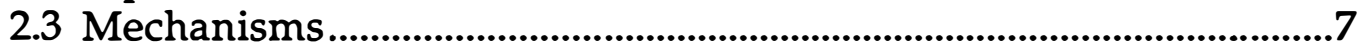

2.4 Kinetics.........................................................................................................

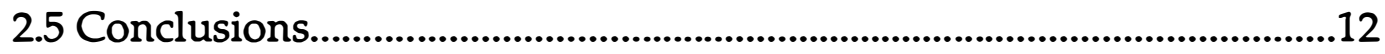

2.6 References for Chapter Two ....................................................................13

3.0 Photocatalytic Oxidation of Ethanol ....................................................................14

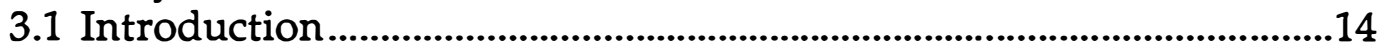

3.2 Experimental.................................................................................................14

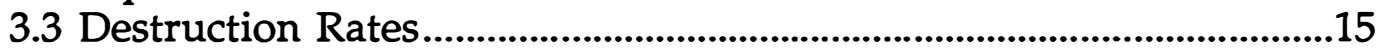

3.4 Products............................................................................................................16

3.5 Mechanisms.........................................................................................18

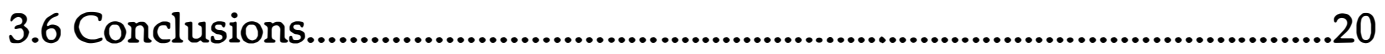

3.7 References for Chapter Three......................................................................20

4.0 Modeling Ethanol ..................................................................................................21

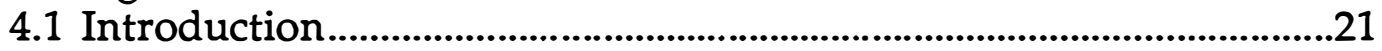

4.2 Experimental...............................................................................................21

4.3 Model Development.......................................................................................23

4.4 Parameter Value Estimation..................................................................24

4.5 Model Results.............................................................................................24

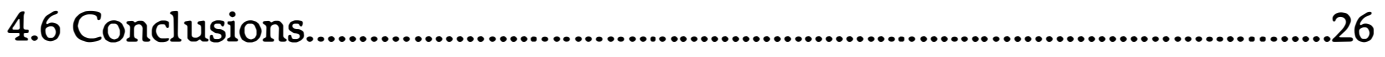

4.7 Recommendations for Future Work .....................................................27

5.0 Field Tests at Coors Brewery...........................................................................28

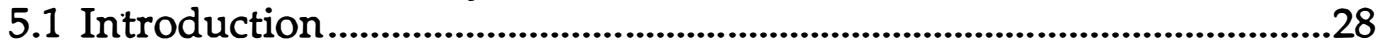

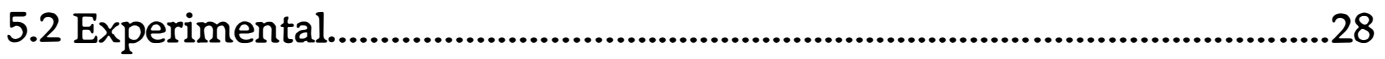

5.3 Results and Discussion ...........................................................................29

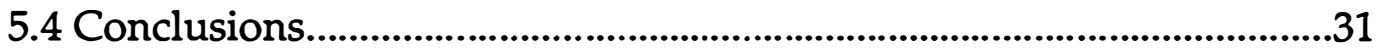

6.0 Results from On-Site Tests at E/M Corporation ................................................32

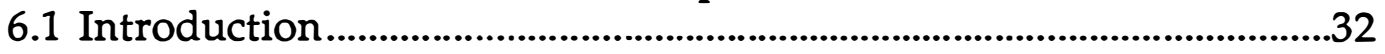

6.2 Experimental....................................................................................................32

6.3 Results and Discussion...............................................................................33

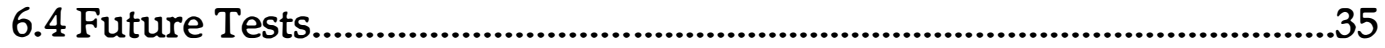

7.0 Rate Enhancement by the Addition of Oxidants ................................................36

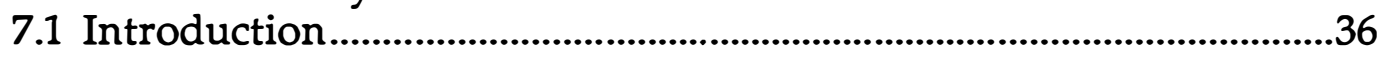

7.2 Preliminary Experiments: Demonstrating the Concept.......................37

7.3 Laboratory Research: Recirculating Reactor..............................................39 
7.4 System and Cost Analysis ..........................................................................41

7.5 Single-Pass Experiments.........................................................................44

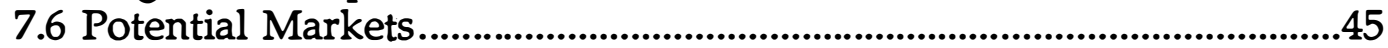

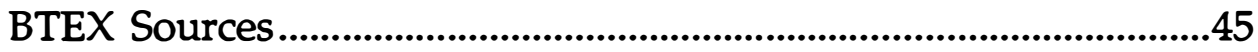

Paint Booths..........................................................................................45

Chemical Industry .............................................................................46

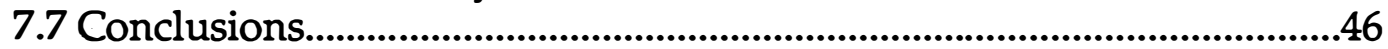

Appendix: Reports of Gas-Phase Photocatalysis in the Literature ......................47 


\section{Executive Summary}

Laboratory experiments of gas-phase photocatalytic oxidation (PCO) at NREL have focused on measurements that can help commercialize this technology for treating gaseous air streams. This effort proceeds earlier NREL work and studies conducted elsewhere which demonstrated the general applicability of PCO. The more recent work has concentrated on:

1) the kinetics of the $\mathrm{PCO}$ process,

2) the formation and destruction of intermediates, and

3) possible enhancements to improve the destruction rates.

The results from these studies will be used to help design large scale PCO equipment and they will be used to evaluate the economics of the PCO process.

For trichloroethylene and ethanol, extensive studies of the rates of destruction have yielded kinetic parameters for the destruction of intermediates as well as the substrate. The kinetics of intermediates is essential for sizing a large scale reactor, as complete conversion to carbon dioxide is often desired. The kinetic data from these laboratory studies has been used for analyzing IT's pilot PCO reactor and has been used to suggest modifications to this unit.

For compounds that are more difficult to destroy (such as the components of BTEX), rate enhancement experiments have been conducted. These compounds represent a very large market for this technology and improvement of the rate of the process should make it competitive. Towards this goal, the enhancement of the destruction of BTEX components have been studied. Experiments have demonstrated that there is a significant increase in the rates of destruction of BTEX with the addition of ozone. Preliminary economic assessments have shown that PCO with ozone may be cost competitive.

Future laboratory experiments of $\mathrm{PCO}$ will focus on refinements of what has been learned. Rate measurements will also be expanded to include other compounds representing significant markets for the PCO technology. As applicable, work will continue on methods to improve the competitiveness of the PCO process. 


\subsection{Introduction}

\subsection{Potential for Gas-Phase Photocatalysis}

Because of increasingly stringent regulations concerning gaseous emissions, there is interest in control technologies that can destroy organic compounds. Emissions of organic compounds can contribute to the formation of urban smog and ozone, acid rain, stratospheric ozone depletion and the greenhouse effect.

Many industrial sources of gaseous emissions contain low levels of organics in high-volume flows. Some examples of industrial operations and the organic emissions associated with them are listed below. Because the flows are high (100 standard cubic feet per minute [SCFM] or more) and the concentrations are low (often less than 100 parts per million [ppm]) many of the well-developed available control technologies are expensive or difficult to permit. Thus, for many applications, development of new oxidation technologies may be critical.

Potential Applications

\begin{tabular}{|cc|}
\hline - Soil and Water Remédiation & - Furniture Manufacturing \\
Chlorinated solvents, BTEX & Volatile Solvents \\
- Painting and Coating Operations & - Printing \\
Volatile Solvents & Volatile Solvents \\
- Electronics Manufacturing & $\bullet$ Dry Cleaners \\
Chlorinated Solvents, Volatile Solvents & Chlorinated Solvents \\
- Fuel Off-loading and Storage & - Breweries \\
BTEX & Ethanol \\
\hline
\end{tabular}

Gas-phase photocatalytic oxidation is a new technology which is being investigated for its potential uses in removing organic compounds from the air. The process consists of passing the contaminated air over an illuminated catalyst (usually titanium dioxide, $\mathrm{TiO}_{2}$ ) at ambient temperatures. The absorption of the light by the catalyst produces reactive species (such as the $\bullet \mathrm{OH}$ radical) which then react with the organic contaminants. The desired end products (though there may be intermediates formed) are carbon dioxide and water. Mineral acids may be formed if halogenated compounds are present. These products are not considered significant health hazards.

\subsection{History of Gas-Phase Photocatalysis}


The first studies of photocatalysis of organic molecules were most concerned with oxidation of paraffins [1], olefins [1] and alcohols [2], though little mention was made of using this process for waste destruction. Fairly recently Dibble and Raupp investigated its use as a waste destruction technique [3-8]. They studied the kinetics of the photocatalytic oxidation (PCO) of trichloroethylene in their first few papers and have examined other compounds since. A number of other researchers have also reported on studies of gas-phase photocatalytic oxidation.

A list of compounds that has been studied in the gas phase is presented in a Table in the Appendix.

\subsection{Early NREL Laboratory Studies}

The first studies at NREL of PCO were concerned with the destruction of chlorinated ethylenes in general and trichloroethylene (TCE) in particular [9]. NREL's molecular beam mass spectrometer (MBMS) was used to monitor the destruction of the TCE and the formation of byproducts. This quick screening apparatus showed that several products, including phosgene, molecular chlorine, dichloroacetyl chloride, carbon dioxide and hydrogen chloride, were formed under a wide variety of conditions. These byproducts were confirmed and quantified later with a gas-phase Fourier-Transform infrared (FTIR) spectrometer. In addition, carbon monoxide was identified using the FTIR.

These results showing undesirable byproducts from TCE were apparently unique in photocatalysis, and a publication discussing the mechanisms of their formation was written for the journal Environmental Science and Technology [9]. (A copy of this article is attached.) This paper evaluates the mechanisms for photocatalytic oxidation of TCE by comparing the products to those formed from other chlorinated ethylenes. From a practical standpoint, it is important that the formation of intermediates in photocatalysis be recognized so that commercial systems can be designed to eliminate harmful emissions. The paper also served to acquaint the technical community with NREL's capabilities and efforts in gas-phase photocatalysis.

Subsequent experiments at NREL focused on expanding the range of compounds that can be treated using gas-phase photocatalysis, and the MBMS was used to screen a number of compounds to determine their susceptibility to the process. A list of the compounds that have been tested is shown in Table 1.1. All of the compounds in this table reacted at rates lower than for TCE. Typically, the reaction rates for these other compounds were ten to one hundred times slower than for TCE. Several of these compounds, notably the aromatics showed little or no photocatalytic activity. Generally, there were few byproducts found in these experiments with the exception of those that involved alcohols and amines. 
TABLE 1.1 Compounds Screened for Photocatalytic Activity

\begin{tabular}{llll}
\hline \hline Compound & Rate & Compound & Rate \\
\hline methanol & $\mathrm{m}$ & benzene & $\mathrm{s}$ \\
ethanol & $\mathrm{m}$ toluene & $\mathrm{s}$ \\
1-propanol & $\mathrm{m}$ ethylbenzene & $\mathrm{m}$ \\
2-propanol & $\mathrm{m}$ xylenes & $\mathrm{m}$ \\
1-butanol & $\mathrm{m}$ dichlorobenzene & $\mathrm{s}$ \\
acetaldehyde & $\mathrm{m} \quad \# 2$ fuel oil & $\mathrm{m}$ \\
propionaldehyde & $\mathrm{m} \quad$ 1,1-dichloroethylene & $\mathrm{f}$ \\
benzaldehyde & $\mathrm{m} \quad$ 1,2-dichloroethylene & $\mathrm{f}$ \\
acetone & $\mathrm{s}$ & trichloroethylene & $\mathrm{f}$ \\
ethyl acetate & $\mathrm{m} \quad$ perchloroethylene & $\mathrm{f}$ \\
butyl acetate & $\mathrm{m}$ dichloroacetyl chloride & $\mathrm{m}$ \\
methylethyl ketone & $\mathrm{m}$ methylene chloride & $\mathrm{s}$ \\
methylisobutyl ketone & $\mathrm{m}$ ethylene & $\mathrm{m}$ \\
acetonitrile & $\mathrm{s}$ ethane & $\mathrm{s}$ \\
propylnitrile & $\mathrm{s} \quad$ decane & $\mathrm{m}$ \\
diisopropyl amine & $\mathrm{m}$ tetraethylethylene & $\mathrm{m}$ \\
propyl amine & $\mathrm{m}$ & \\
butyl amine & $\mathrm{m}$ & \\
t-butyl amine & $\mathrm{s}$ & \\
sec-butly amine & $\mathrm{m}$ & \\
diethyl amine & $\mathrm{m}$ & \\
\hline \hline
\end{tabular}

\subsection{Format of Report}

This report is divided into chapters describing distinct laboratory PCO projects. Since the chapters are presented as independent descriptions, there may be some repetition.

\subsection{References for Chapter One}

1. Courbon, A. F. ,. M., Juillet, F., Lisachenko, A. A., Martin, J., and Teichner, S. J. "Photocatalytic activity of nonporous titanium dioxide (anatase)." Kinet. Katal. 14, no. 1 (1973): 110-17.

2. Ait Ichou, I., Formenti, M., and Teichner, S. J. "Photocatalytic dehydrogenation of isopropanol on $\mathrm{Pt} / \mathrm{TiO}_{2}$ catalysts in connection with water photosplitting." Stud. Surf. Sci. Catal. 19 (1984): 297-307; Ait Ichou, I., Formenti, M., Pommier, B., and Teichner, S. J. "Photocatalytic dehydrogenation of isopropanol on $\mathrm{Pt} / \mathrm{TiO}_{2}$ catalysts." J. Catal. 91, no. 2 (1985): 293-307; Ait Ichou, I., Formenti, M., and Teichner, S. J. "Reverse spillover of hydrogen adsorbed species in dehydrogenation photocatalysis on platinum-titania catalysts." Stud. Surf. Sci. Catal. 17 (1983): 63-75. 
3. Raupp, G. B., Junio, C. T., Mallela, R. K., and Phillips, L. A. "Destruction of organics in gaseous streams over UV-excited titania." Air and Waste Management Association, Kansas City, Missouri, 21 June 1992.

4. Dibble, L. A., and Raupp, G. B. "Fluidized bed photocatalytic oxidation of trichloroethylene in contaminated air streams." Environ. Sci. Technol. 26, no. 3 (1993): 492-5.

5. Dibble, L. A., and Raupp, G. B. "Heterogeneous photocatalysis: A novel approach for the degradation of volatile organic water pollutants." Ariz. Hydrol. Soc. 1st Ann. Symp. "Survival in the Desert: Water Quality and Quantity Issues into the 21st Century," 221-229. Phoenix, Ariz., 16 September 1988.

6. Raupp, G. B., and Dibble, L. A. Gas-solid photocatalytic oxidation of environmental pollutants. In EP. WO $9104094 \mathrm{~A} 1 \mathrm{~W}$ : CA, JP RW: AT, BE, CH, DE, DK, ES, FR, GB, IT, LU, NL, SE. WO 90-US4996, 4 Sep 1990. (4 April 1991).

7. Dibble, L. A. "Gas-solid heterogeneous photocatalytic oxidation of trichloroethylene by near-ultraviolet-illuminated titanium dioxide." Ph.D. diss., Arizona State Univ, 1989.

8. Dibble, L. A., and Raupp, G. B. "Kinetics of the gas-solid heterogeneous photocatalytic oxidation of trichloroethylene by near UV illuminated titanium dioxide." Catal. Lett. 4, no. 4-6 (1990): 345-54.

9. Nimlos, M. R., Jacoby, W. A., Blake, D. M., and Milne, T. A. "Direct mass spectrometric studies of the destruction of hazardous wastes 2 . Gas phase photocatalytic oxidation of trichloroethylene over $\mathrm{TiO}_{2}$ : products and mechanisms." Environ. Sci. Technol. 27 (1993): 732-40. 


\subsection{Photocatalytic Oxidation of Trichloroethylene}

\subsection{Introduction}

Trichloroethylene (TCE) is probably the most pervasive groundwater contaminant in the United States [1]. Many of the current technologies to treat it are inadequate because they do not destroy the TCE, but merely transfer it to another phase.

Gas-phase photocatalytic oxidation (PCO) may be a useful treatment for these TCE-contaminated water supplies. TCE can be removed from the water using conventional air strippers and then treated in the gas phase using PCO. PCO is able to treat low levels of TCE contamination, and it works well under humid conditions.

Of key importance in the development of PCO for TCE destruction is the measurement of kinetic parameters. These parameters are necessary for scale-up calculations and cost estimates. They must account for both the destruction of TCE and the destruction of intermediates. Potentially toxic products from TCE include dichloroacetyl chloride (DCAC), phosgene, molecular chlorine and hydrogen chloride. Since DCAC reacts on the illuminated catalyst surface, the kinetic parameters for this reaction need to be measured. Phosgene, molecular chlorine and hydrogen chloride react slowly on the catalyst and can be removed using a caustic scrubber and technology that is well developed. But determination of kinetic parameters still is necessary for the destruction of TCE, formation of DCAC and destruction of DCAC.

\subsection{Experimental}

The experiments for this study were conducted by passing gasses containing TCE through a single-pass, annular photocatalytic reactor configuration and then analyzing the products using the FTIR. Samples make a single pass through the photocatalytic reactor at flow rates on the order of $10 \mathrm{l} / \mathrm{min}$. The reactor diameter was $1.6 \mathrm{~mm}$ and the catalyst surface area was $10.3 \mathrm{~cm}$ [4]. Analysis is performed by the FTIR gas analyzer (Nicolet 8220) directly sampling the entire reactor effluent in flow-through mode without splitting or dilution. Most of the experimental work in this investigation was performed under a set of standard operating conditions: 500 torr pressure and $294 \mathrm{~K}$. Annular photocatalytic reactors coated with Degussa P-25 $\mathrm{TiO} 2$ (anatase) were used. The catalyst is applied to the outer annular surface (the inside surface of a pyrex reactor tube) with a wash coat technique. A cylindrical light source comprises the inner annulus, which is typically a fluorescent black light (Sylvania F8T5BLB, $8 \mathrm{~W}$, spectral maximum at $356 \mathrm{~nm}$ ). A germicidal lamp (Sylvania G8T5, $8 \mathrm{~W}$, spectral maximum at $254 \mathrm{~nm}$ ) was also tested. 


\subsection{Mechanisms}

The PCO mechanism for the TCE was first investigated using the MBMS [2]. For this study, the mass spectra of products from 1,2-dichloroethylene, 1,1dichloroethylene and perchloroethylene were compared with the mass spectra of products from TCE. With all of the chlorinated ethylenes, acetyl chlorides were identified in the product streams. These products were later confirmed and quantified using the FTIR. Similar products were found in homogeneous gas-phase studies conducted by others [3]. These homogeneous experiments were initiated by chlorine atoms and involved chlorine atom chain reactions. Table 2.2 compares the products observed in these homogeneous reactions with those found from PCO. The quantum yields for the homogeneous experiments are the number of reactions per initial chlorine atom and are thus a measure of the chain length. Because similar products are found, it is assumed that the reaction mechanism for the destruction of TCE (and chlorinated ethylenes in general) involves a chlorine atom chain mechanism.

Table 2.2 Comparison of Products from Homogeneous Cl-Atom Initiated Oxidation and Photocatalytic Oxidation

\begin{tabular}{|c|c|c|c|c|}
\hline \multirow[b]{2}{*}{ Compound } & \multicolumn{2}{|c|}{$\begin{array}{l}\text { Results from Homogeneous } \\
\text { Reaction [3] }\end{array}$} & \multicolumn{2}{|c|}{$\begin{array}{l}\text { Results From Photocatalytic } \\
\text { Oxidation }\end{array}$} \\
\hline & Products (percent) & $\begin{array}{l}\text { Quantum } \\
\text { Yield }\end{array}$ & Products & $\begin{array}{l}\text { Quantum } \\
\text { Yield }\end{array}$ \\
\hline $\mathrm{Cl}_{2} \mathrm{CCCl}_{2}$ & $\begin{array}{c}\mathrm{CCl}_{3} \mathrm{CClO}(75), \\
\mathrm{COCl}_{2}(25)\end{array}$ & 300 & $\begin{array}{c}\mathrm{CCl}_{3} \mathrm{CClO}, \\
\mathrm{COCl}_{2}\end{array}$ & 0.08 \\
\hline $\mathrm{ClHCCCl}_{2}$ & $\begin{array}{l}\mathrm{CCl}_{2} \mathrm{HCClO}(90), \\
\mathrm{COCl}_{2}\end{array}$ & 200 & $\begin{array}{l}\mathrm{CCl}_{2} \mathrm{HCClO}, \\
\mathrm{COCl}_{2}\end{array}$ & 0.22 \\
\hline $\mathrm{Cl}_{2} \mathrm{CCH}_{2}$ & $\begin{array}{l}\mathrm{CH}_{2} \mathrm{ClCClO}(98), \\
\mathrm{COCl}_{2}\end{array}$ & 172 & $\begin{array}{l}\mathrm{CH}_{2} \mathrm{ClCC} C \mathrm{O} \\
\mathrm{COCl}_{2}\end{array}$ & 0.14 \\
\hline c-ClHCCClH & $\begin{array}{l}\mathrm{CHClO}(71) \\
\mathrm{COCl}_{2}(3)\end{array}$ & 21.5 & $\begin{array}{l}\mathrm{CCl}_{2} \mathrm{HCClO}, \\
\mathrm{COCl}_{2}\end{array}$ & 0.06 \\
\hline $\mathrm{t}-\mathrm{ClHCCClH}$ & $\begin{array}{l}\mathrm{CHClO}(71), \\
\mathrm{COCl}_{2}(3)\end{array}$ & 21.5 & $\begin{array}{l}\mathrm{CCl}_{2} \mathrm{HCClO}, \\
\mathrm{COCl}_{2}\end{array}$ & 0.05 \\
\hline
\end{tabular}

That the destruction proceeds through a chain reaction accounts for the fast reaction rates observed for TCE in comparison with other compounds where chain reactions are unlikely. Table 2.3 shows the reaction rates for different olefins as measured with the FTIR. The reaction rates for chlorinated ethylenes is clearly larger than for those of nonchlorinated compounds. Nonchlorinated compounds are unlikely to have chain reactions, and their rates of reaction are much slower than those for chlorinated olefins. It is likely that part of the difference in reaction rates between chlorinated and nonchlorinated compounds derives from differences 
in rates of adsorption, but clearly most of the difference results from differences in intrinsic heterogeneous reaction rates. Since all of these compounds have comparable rates of reaction with hydroxyl radicals, the high rates of reaction for TCE suggests that most of the TCE is destroyed by chlorine atom chain reactions.

Table 2.3 PCO Reaction Rates for Olefins

\begin{tabular}{lll}
\hline \hline Compound & Chemical Formula & Rate $\left(\mu \mathrm{mol} / \mathrm{m}^{2} / \mathrm{s}\right)$ \\
\hline Trichloroethylene & $\mathrm{ClHC}=\mathrm{CCl}_{2}$ & 100 \\
Perchloroethylene & $\mathrm{Cl}_{2} \mathrm{C}=\mathrm{CCl}_{2}$ & 72 \\
1,2-Dichloroethylene & $\mathrm{ClHC}=\mathrm{CClH}$ & 46 \\
Propene & $\mathrm{CH}_{3} \mathrm{HC}=\mathrm{CH}_{2}$ & 16 \\
Ethylene & $\mathrm{H}_{2} \mathrm{C}=\mathrm{CH}_{2}$ & 1 \\
Tetramethyl ethylene & $\left(\mathrm{CH}_{3}\right)_{2} \mathrm{C}=\mathrm{C}\left(\mathrm{CH}_{3}\right)_{2}$ & 3 \\
\hline
\end{tabular}

For TCE, the chlorine atom chain reaction mechanism in homogeneous gasphase chemistry leads to the formation of dichloroacetyl chloride (DCAC) by the following stoichiometry:

$$
\mathrm{ClHC}=\mathrm{CCl}_{2}+\mathrm{Cl}+1 / 2 \mathrm{O}_{2}-->\mathrm{CHCl}_{2} \mathrm{CClO}+\mathrm{Cl}
$$

The formation of phosgene and the other products likely results from the destruction of DCAC. Phosgene can be formed by a reaction that involves chlorine atom attack of TCE directly, but this is not a chain reaction mechanism and is not likely to be a major reaction channel.

Figure 2.1 presents a plot of the ratios of products from PCO experiments conducted using DCAC as the starting material. The experiments in this plot were conducted using a variety of starting conditions (different flow rates, water vapor concentrations, DCAC concentrations). The plot presents the ratio of carbon monoxide to phosgene and the ratio of carbon dioxide to carbon monoxide. As can be seen, the ratio $\mathrm{CO} / \mathrm{COCl}_{2}$ remains roughly constant at 1 under all of the experimental conditions. However, the ratio $\mathrm{CO}_{2} / \mathrm{CO}$ increases with increasing water concentration. The ratio $\mathrm{CO} / \mathrm{COCl}_{2}=1$ seems to suggest that there is a reaction channel which forms carbon monoxide and phosgene and that one of the carbon atoms of the DCAC will result in $\mathrm{CO}$ and one will result in $\mathrm{COCl}_{2}$. The following reaction mechanism is a possible pathway for this destruction:

$$
\begin{aligned}
& \mathrm{CHCl}_{2} \mathrm{CClO}+\cdot \mathrm{OH} \rightarrow \cdot \mathrm{CCl}_{2} \mathrm{CClO}+\mathrm{H}_{2} \mathrm{O} \\
& \cdot \mathrm{CCl}_{2} \mathrm{CClO}+\mathrm{O}_{2} \rightarrow \cdot \mathrm{OOCCl}_{2} \mathrm{CClO} \\
& 2 \cdot \mathrm{OOCCl}_{2} \mathrm{CClO} \rightarrow \cdot \mathrm{OCCl}_{2} \mathrm{CClO}+\mathrm{O}_{2} \\
& \cdot \mathrm{OCCl}_{2} \mathrm{CClO} \rightarrow \mathrm{COCl}_{2}+\mathrm{CO}+\mathrm{Cl}
\end{aligned}
$$


The fact that the ratio $\mathrm{CO}_{2} / \mathrm{CO}$ increases with increasing water vapor concentration suggests that there is another reaction channel involving water which does not produce phosgene or carbon monoxide. A likely reaction sequence for the evolution of carbon dioxide is the hydrolysis of DCAC, followed by a photo Kolbe reaction.

$$
\begin{aligned}
& \mathrm{CHCl}_{2} \mathrm{CClO}+\mathrm{H}_{2} \mathrm{O} \rightarrow \mathrm{CHCl}_{2} \mathrm{CO}_{2} \mathrm{H}+\mathrm{HCl} \\
& \mathrm{CHCl}_{2} \mathrm{CO}_{2} \mathrm{H}+\mathrm{hv}\left(\mathrm{TiO}_{2}\right) \rightarrow--\mathrm{CHCl}_{2} \bullet+\mathrm{CO}_{2}+\mathrm{H}
\end{aligned}
$$

The fate of the dichloromethyl radical is unclear.

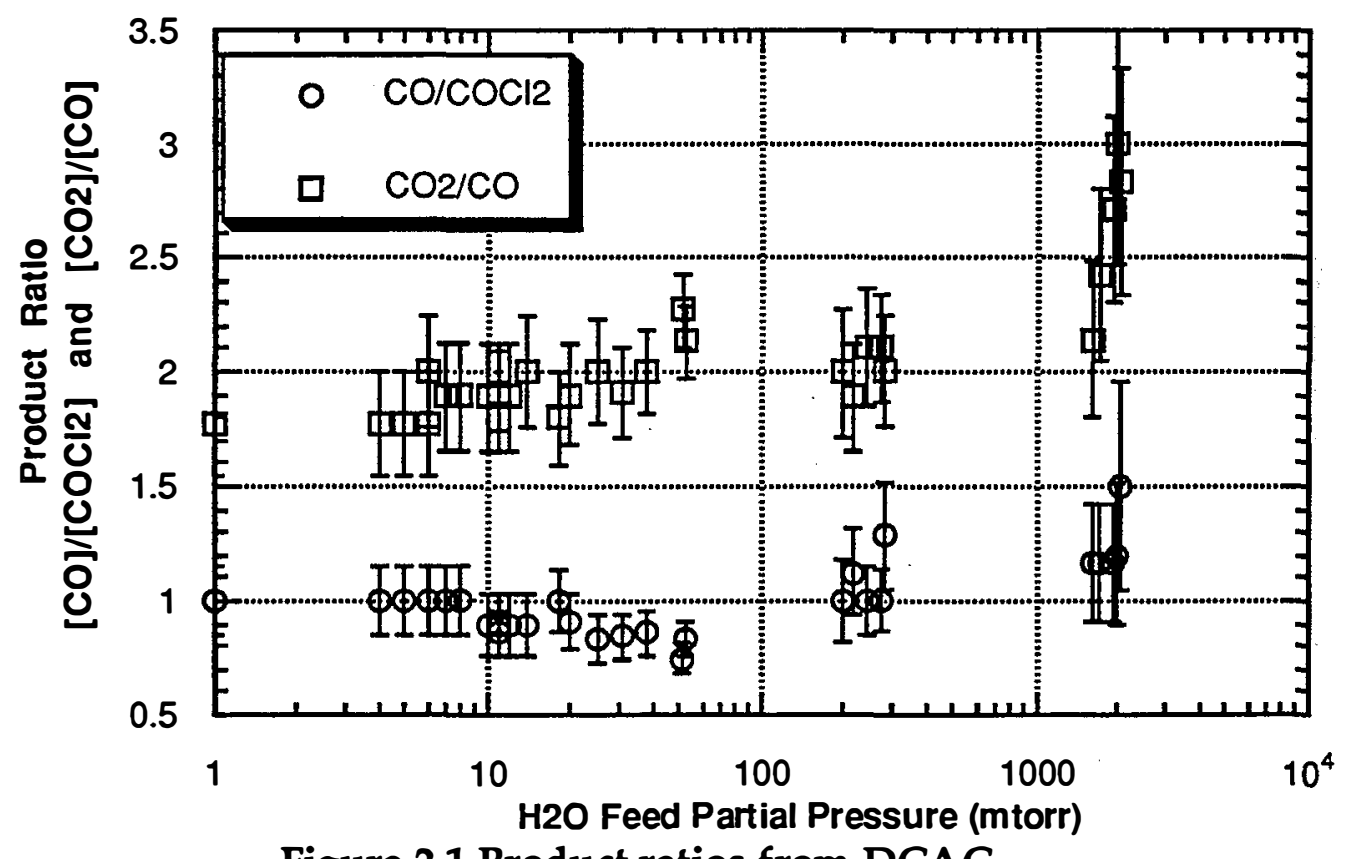

Figure 2.1 Product ratios from DCAC

The product ratios from TCE were different from DCAC, suggesting that there was an additional reaction channel for the destruction of TCE. The ratio $\mathrm{CO} / \mathrm{COCl}_{2}$ was found to be about 0.5 , and the ratio $\mathrm{CO}_{2} / \mathrm{COCl}_{2}$ was about 1 .

\subsection{Kinetics}

In order to model the kinetics of the destruction of TCE and the formation and destruction of the products, it is necessary to build a global mechanism that accounts for the different reaction channels. As discussed above, the global mechanism for the photocatalytic oxidation of TCE can be summarized as follows:

TCE ---(major)---> DCAC 


$$
\begin{aligned}
& \text { TCE ---(minor)--> Phosgene + Products } \\
& \text { DCAC ----> Carbon Monoxide + Phosgene } \\
& \text { DCAC }+\mathrm{H}_{2} \mathrm{O} \longrightarrow \text { Carbon Dioxide + Products }
\end{aligned}
$$

As a first order approximation, it can be assumed that the removal of TCE follows simple Langmuir-Hinshelwood Kinetics

$$
\text { rate }=-\mathrm{d}[\mathrm{TCE}] / \mathrm{dt}=\mathrm{kK}[\mathrm{TCE}] /(1+\mathrm{K}[\mathrm{TCE}])
$$

where [TCE] is the TCE concentration, $\mathrm{k}$ is the intrinsic surface rate constant and $\mathrm{K}$ is the adsorption constant for TCE. Obviously, this is a simplification of the intrinsic kinetics. In reality, $\mathrm{k}$ is dependent upon the number of chlorine atoms, which are themselves dependent upon the TCE concentration. Nevertheless, this model provides a starting point to consider a more complete model. Figure 2.2 presents a plot of the data from the single pass annular reactor and a fit to the data using rate equation (2.12). The parameters from this fit are $\mathrm{K}=0.012 \mathrm{ppm}^{-1}$ and $\mathrm{k}=790$ $\mathrm{ppm} / \mathrm{s} / \mathrm{cm}^{2}$. The fit appears to extend to fairly low concentrations.

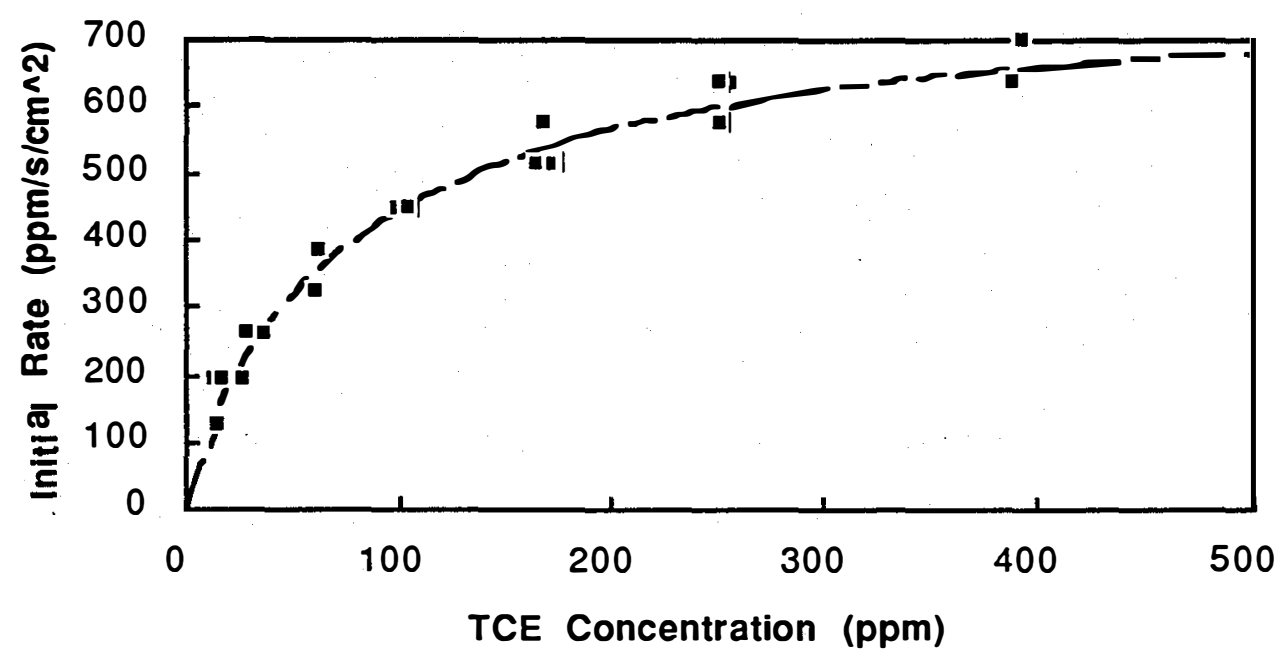

Figure 2.2 Initial rate of destruction of TCE as a function of concentration

To get a complete picture of the photocatalytic destruction of TCE, destruction of the main intermediate (DCAC) was also measured. Because of difficulties with handling this material, it was difficult to obtain differential data and integral data was instead collected. Figure 2.3 presents a plot of the destruction data (square points) for DCAC as a function of the starting concentration. The line in this plot was obtained by estimating Langmuir-Hinshelwood kinetic parameters to fit the 
data. A simplified rate form such as that shown in Equation 2.12 was used. The parameters obtained from this fit are $\mathrm{K}=0.5 \mathrm{ppm}^{-1}$ and $\mathrm{k}=68 \mathrm{ppm} / \mathrm{s} / \mathrm{cm}^{2}$.

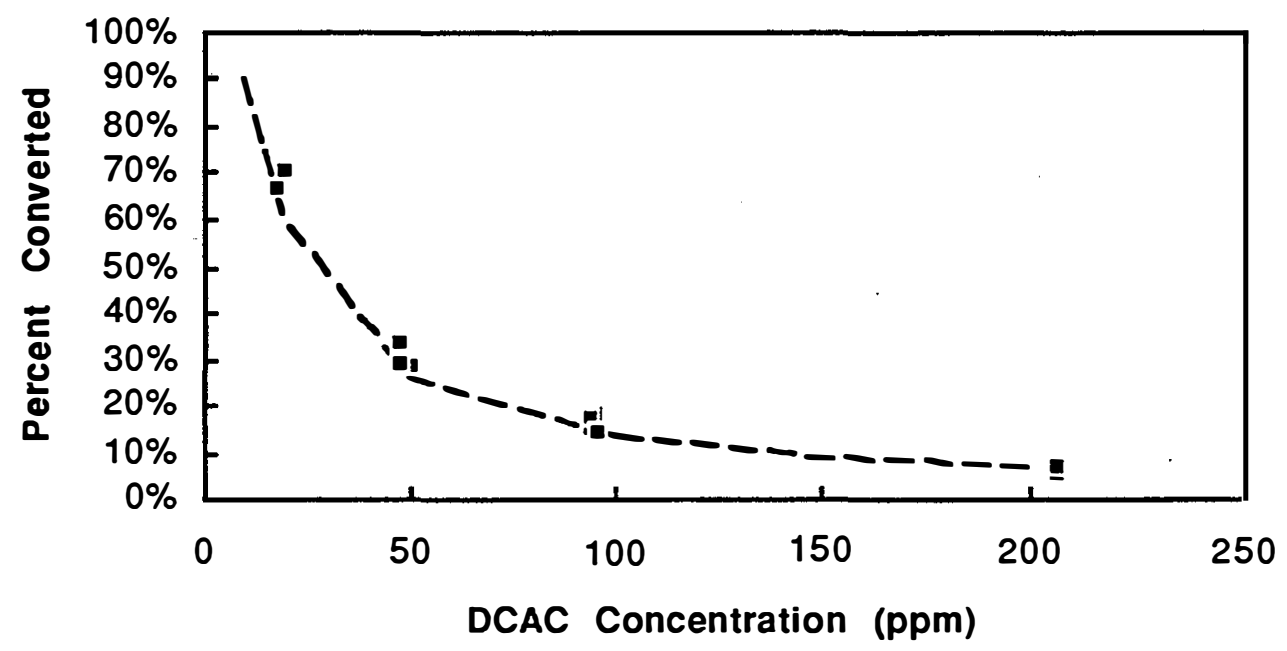

Figure 2.3 Integral destruction of DCAC

Based upon the mechanism data presented in the previous section, the kinetics of the evolution of products from PCO can be estimated. For kinetic modeling the following reaction scheme will be used:

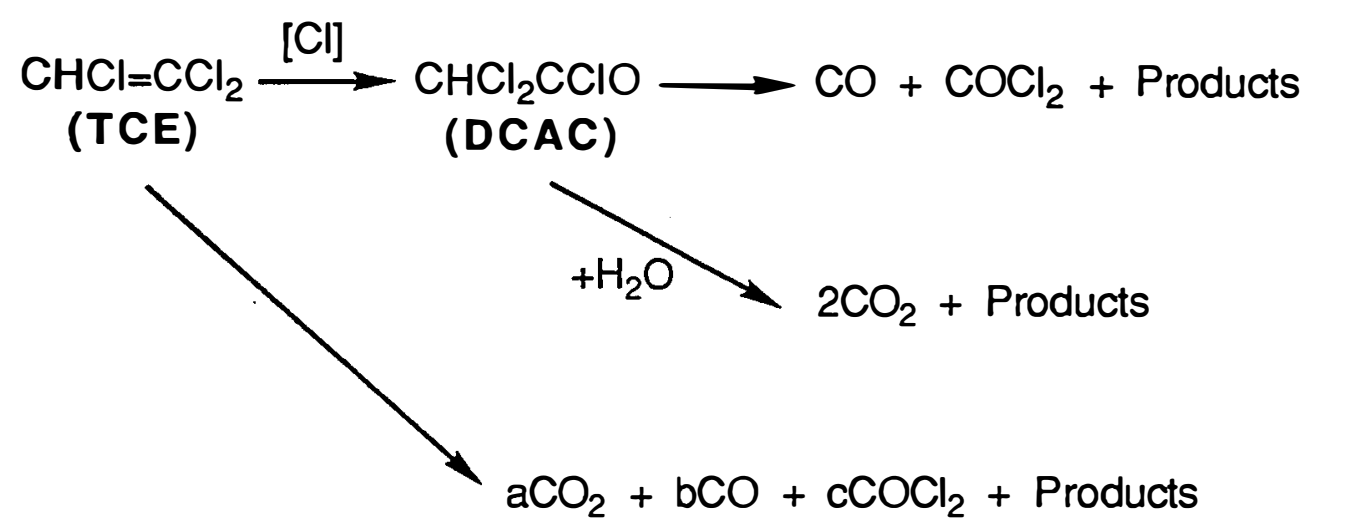

Most of the TCE will react by a chain mechanism to give DCAC, which can react to give $\mathrm{CO}$ and $\mathrm{COCl}_{2}$, or which can be hydrolyzed to give two $\mathrm{CO}_{2}$ molecules. At low concentrations of water, the branching ratio for the hydrolysis reaction is about $50 \%$. This explains the ratio $\mathrm{CO}_{2} / \mathrm{CO} / \mathrm{COCl}_{2}=2 / 1 / 1$. The TCE also reacts to directly form $\mathrm{CO}_{2}, \mathrm{CO}$ and $\mathrm{COCl}_{2}$. To model the evolution of products from TCE, a branching ratio for TCE going through DCAC, compared to going directly to products, was assumed. The kinetic parameters determined from the experiments with TCE (Figure 2.2) and 
DCAC (Figure 2.3) were used as starting values. These parameters and the branching ratio for TCE were adjusted to fit the data. Figures 2.4 and 2.5 show the results of a reasonable fit.

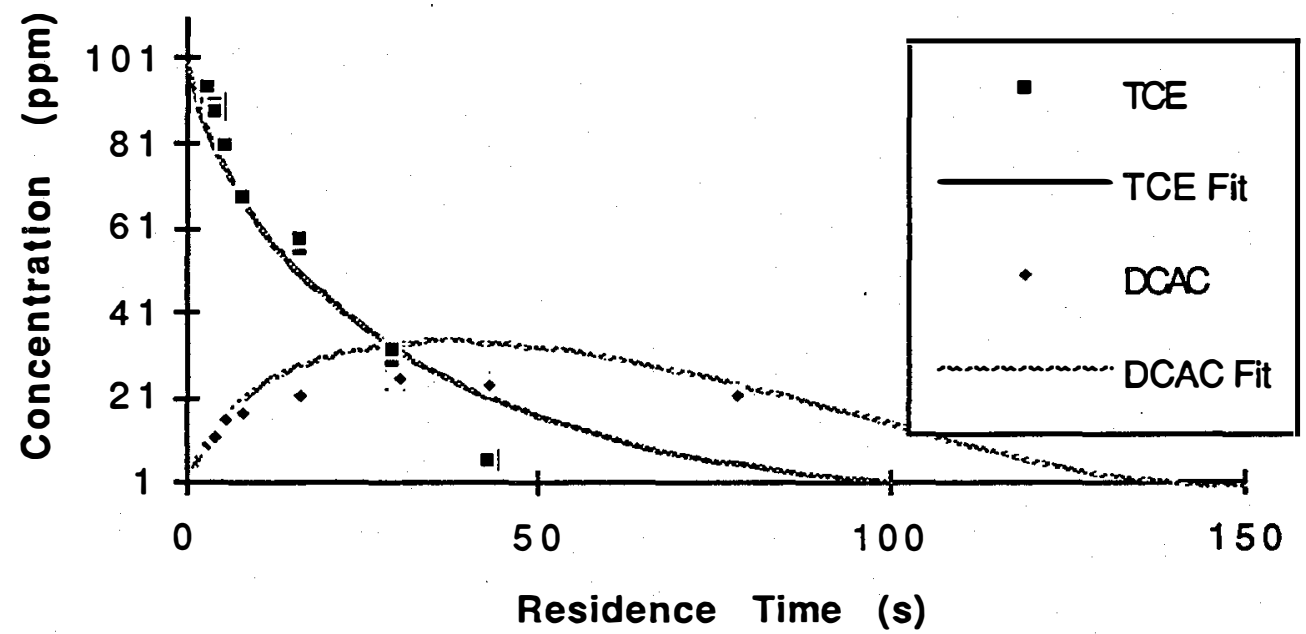

Figure 2.4 Fit of destruction of TCE and formation and removal of DCAC

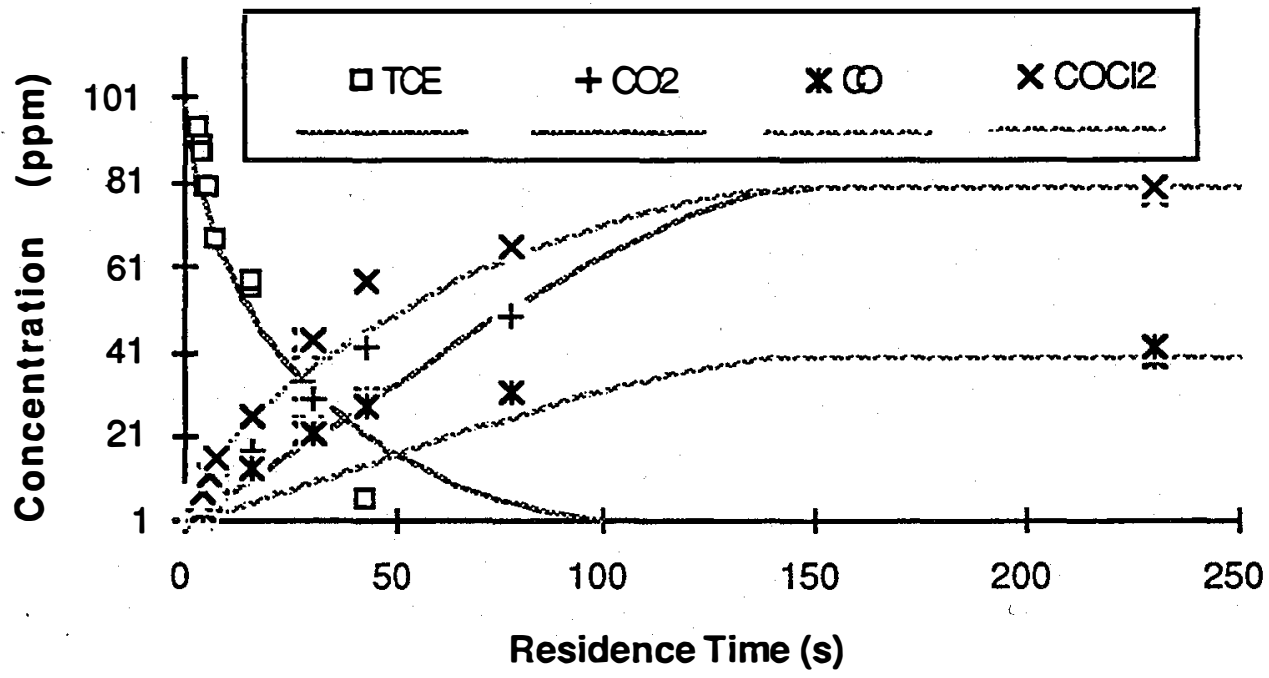

Figure 2.5 Fit of destruction of TCE and formation of $\mathrm{CO}_{2}, \mathrm{CO}$, and $\mathrm{COCl}_{2}$

\subsection{Conclusions}

The reaction sequence and the kinetics for the photocatalytic oxidation of TCE have been studied. Both the reaction mechanism and the kinetics are quite complicated. Most of the TCE is destroyed by a chain reaction mechanism in which DCAC is formed. This can react further to form $\mathrm{CO}_{2}, \mathrm{CO}$ and $\mathrm{COCl}_{2}$. TCE can also react directly to form the above mentioned products. 
DCAC is formed. This can react further to form $\mathrm{CO}_{2}, \mathrm{CO}$ and $\mathrm{COCl}_{2}$. TCE can also react directly to form the above mentioned products.

Table 2.4 Parameters Used to Fit PCO Data for TCE

Kinetic Parameters

TCE $\quad$ DCAC

$\mathrm{k}\left(\mathrm{ppm} / \mathrm{s} / \mathrm{cm}^{2}\right) \quad 1000 \quad 30$

$\mathrm{K}\left(\mathrm{ppm}^{-1}\right) \quad 0.02 \quad 0.15$

Branching Ratio for Direct Reaction of TCE (Reaction 2.15): 0.3

Stoichiometry of Reaction 2.15: $\quad 0.33 \mathrm{CO}_{2}+0.17 \mathrm{CO}+1.5 \mathrm{COCl}_{2}$

Branching Ratio of Hydrolysis of DCAC (Reaction 2.14): 0.5

\subsection{References for Chapter Two}

1. Dyksen, J. E., Hess, A. F. J.-Am. Water Works Assoc. (1983): 394-403.

2. Nimlos, M. R., Jacoby, W. A., Blake, D. M., and Milne, T. A. "Direct mass spectrometric studies of the destruction of hazardous wastes 2 . Gas phase photocatalytic oxidation of trichloroethylene over $\mathrm{TiO}_{2}$ : products and mechanisms." Environ. Sci. Technol. 27 (1993): 732-40.

3. Sanhueza, E., Hisatsune, I. C., Heiklen, J. Chem. Rev. 76 (1976):801-826.

4. Jacoby, W. A., Ph. D. Thesis, University of Colorado, 1993. 


\subsection{Photocatalytic Oxidation of Ethanol}

\subsection{Introduction}

Ethanol is a solvent that is commonly used in a number of industrial applications including spraying and coating industries. In addition, ethanol emissions from bakeries and breweries are coming under stricter controls. In many cases the emissions containing ethanol are high-volume with low concentration of the organic. This makes air emissions containing ethanol likely candidates for PCO treatment.

In order to evaluate $\mathrm{PCO}$ as a viable control technology, it is important to show that the cost and size of a system is competitive with existing control techniques. Towards this end, laboratory measurements of intrinsic kinetic parameters are necessary. These parameters can then ideally be used for scale-up and cost analysis of treatment systems for any waste stream.

Most laboratory kinetic studies fall short in that only substrate removal is considered. This may be inadequate because PCO often leads to the formation of intermediates, which can be as toxic as the starting material. Fortunately, these intermediates are often reactive, but it is necessary that the kinetics account for the formation and destruction of the intermediates as well as the substrate.

Ethanol is an ideal model compound for the kinetic study of photocatalysis because:

1) It reacts more slowly than TCE and the reaction is not mass transportlimited in most reactors.

2) It is a simple molecule with a simple reaction mechanism.

3) The substrate, intermediates and products can be measured using conventional analytical techniques (gas chromatography and FTIR spectroscopy).

\subsection{Experimental}

The experimental equipment used for this study was primarily the recirculating batch reactor shown in Figure 3.1. In experiments with this apparatus a sample of ethanol at known concentration was recirculated from a 22-L reservoir to the reactor and back to the reservoir. The gas was pumped using a Teflon-coated diaphragm pump. The reactor was a series of 3/8-in. Pyrex tubes coated on the inside with titanium dioxide (Degussa P25) and illuminated from the outside by a bank of black lights. The effective residence time in the reactor could be determined by taking the actual time and multiplying by the ratio of the volume of the reactor to 
the total volume of the system.

The concentrations of ethanol and its intermediates and products were followed using a Hewlet Packard 5890 gas chromatograph (GC) or a MTI P200 gas chromatograph. The HP 5890 was configured with a OV1 capillary column and a flame ionization detector for analyzing organics and a Haysep packed column and a thermal conductivity detector (TCD) for carbon dioxide and water. The MTI had an OV1 and a Haysep column with two TCD detectors.

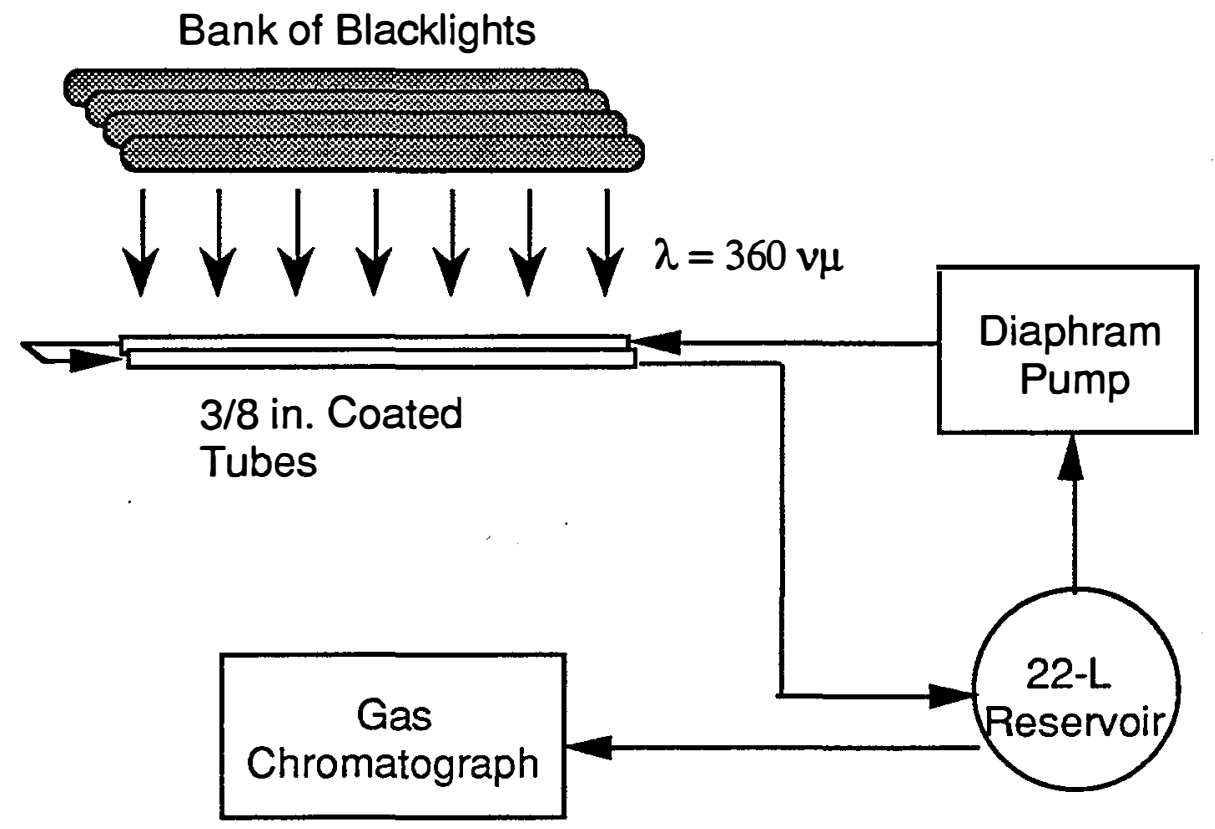

Figure 3.1 Schematic diagram of recirculating batch reactor

\subsection{Destruction Rates}

Figure 3.2 shows the results of a typical batch experiment with ethanol. This type of profile is typical for gas-phase photocatalysis. At the start of the experiment the reaction is kinetic-limited and at the end it is adsorption-limited. This type of decay profile can often be accurately described using the Langmuir-Hinshelwood rate formalism which has the following functional form:

$$
\mathrm{d}[\mathrm{EtOH}] / \mathrm{dt}=\mathrm{kK}[\mathrm{EtOH}] /(1+\mathrm{K}[\mathrm{EtOH}])
$$

where $[\mathrm{EtOH}]$ is the gas-phase concentration of the ethanol, $\mathrm{k}$ is the rate of reaction for the adsorbed ethanol, and $\mathrm{K}$ is the adsorption constant. This rate form is best visualized by the following reaction mechanism:

$$
\begin{array}{ll}
\mathrm{EtOH} \rightarrow \mathrm{EtOH}_{\mathrm{a}} & \left(\mathrm{k}_{\mathrm{a}}\right) \\
\mathrm{EtOH}_{\mathrm{a}} \rightarrow \mathrm{EtOH} & \left(\mathrm{k}_{\mathrm{d}}\right)
\end{array}
$$


$\mathrm{EtOH}_{\mathrm{a}}$-> Products (k)

where $\mathrm{EtOH}_{\mathrm{a}}$ is the adsorbed ethanol, $\mathrm{k}_{\mathrm{a}}$ is the adsorption rate constant, and $\mathrm{k}_{\mathrm{d}}$ is the desorption rate constant. The adsorption constant, $K$, is equal to the ratio $k_{a} / \mathrm{kid}$.

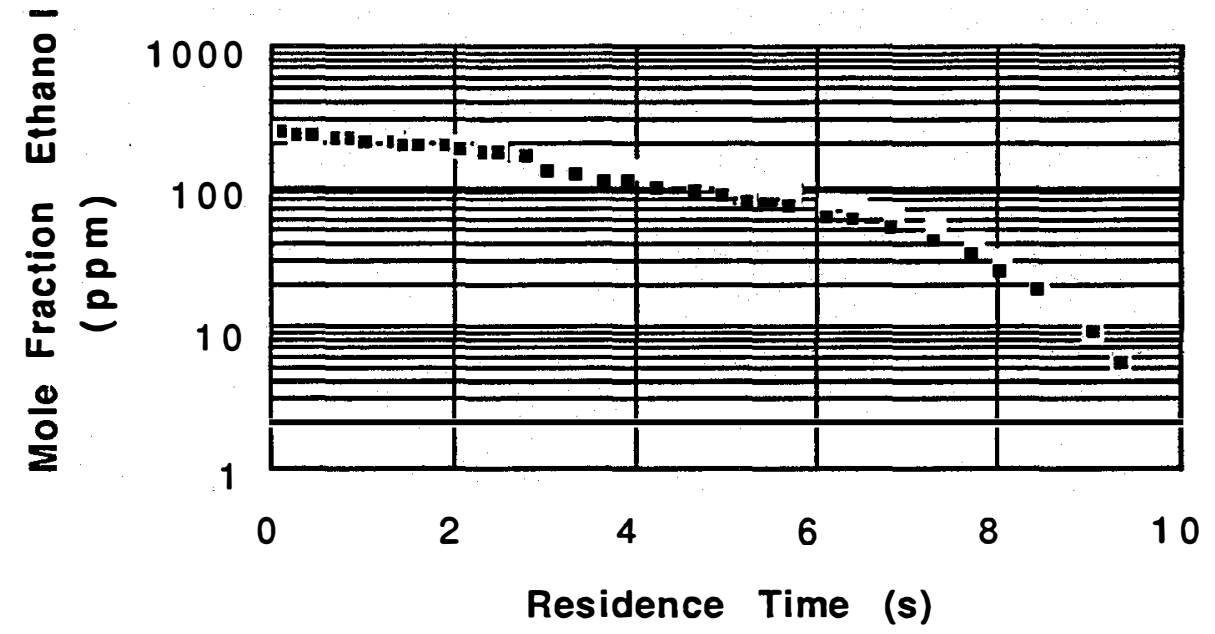

Figure 3.2 Photocatalytic removal of ethanol in recirculating batch reactor

\subsection{Products}

As mentioned above, it is important to account for all intermediates formed during PCO. For ethanol, the primary products formed include acetaldehyde (as an intermediate), carbon dioxide and water. The formation of acetaldehyde is consistent with earlier studies of the photocatalysis of other alcohols[1,2]. These studies showed that ketones or aldehydes are formed from the photocatalytic oxidation of alcohols.

Figure 3.3 shows a plot of the time profiles of the ethanol and the major products from PCO as a function of residence time. As can be seen, the acetaldehyde is formed early, but then reacts. The carbon dioxide is formed later. This is suggestive of a mechanism in which the ethanol reacts to form acetaldehyde, which then reacts to form carbon dioxide. Also shown in this figure is a plot of the carbon balance as a function of residence time. The carbon balance is based upon the initial ethanol concentration and takes into account the acetaldehyde and carbon dioxide. As can be seen from this figure, the carbon is accounted for with ethanol, acetaldehyde and carbon dioxide at the beginning of the run and at the end of the run. However, during the middle of the run the carbon balance is below 100 percent, indicating that some other carbonaceous species is present. Furthermore, the dip in the carbon balance appears to occur after the acetaldehyde, indicating that this unknown species is an intermediate between acetaldehyde and carbon dioxide. In all experiments with ethanol, this dip was seen. 


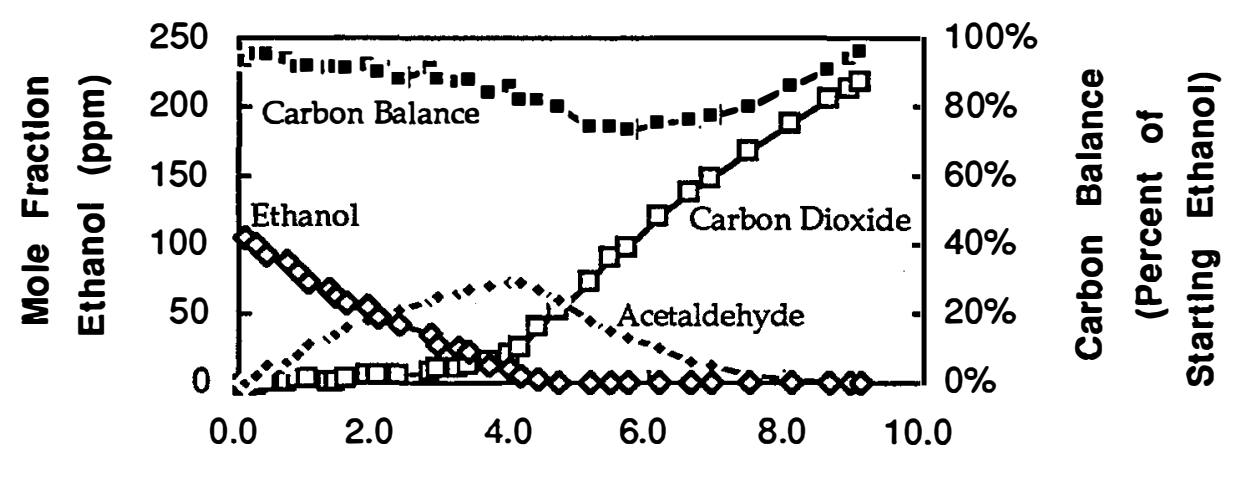

Residence Time (s)

Figure 3.3 Plot of ethanol and products as a function of residence time

To help unravel the chemical pathways important in this process, experiments were conducted using acetaldehyde as the starting material. Figure 3.4 shows a plot of the results of one of these experiments. As can be seen, the dip in the carbon balance is also present. This confirms the presence of another intermediate between acetaldehyde and carbon dioxide.

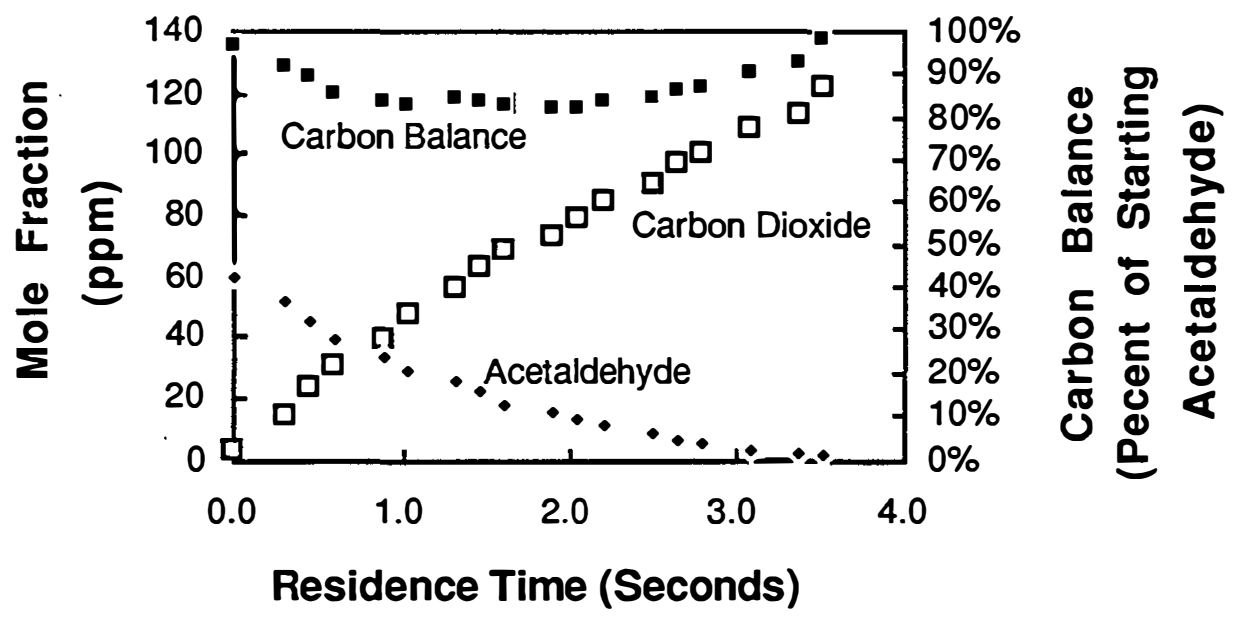

Figure 3.4 Plot of acetaldehyde and products as a function of residence time.

To help identify the other intermediates in the photocatalytic oxidation of ethanol we have conducted a number of tests using a gas-phase FTIR. These experiments were conducted using both a single-pass reactor and a recirculating batch reactor. From these experiments we have identified two other intermediates: formaldehyde and formic acid. In Figures 3.5 and 3.6 FTIR spectra are presented that compare reference spectra for these compounds to spectra taken of the reaction 
products. As can be seen, the identification of these products is unambiguous. Figure 3.7 shows the results from a run using a recirculating reactor.

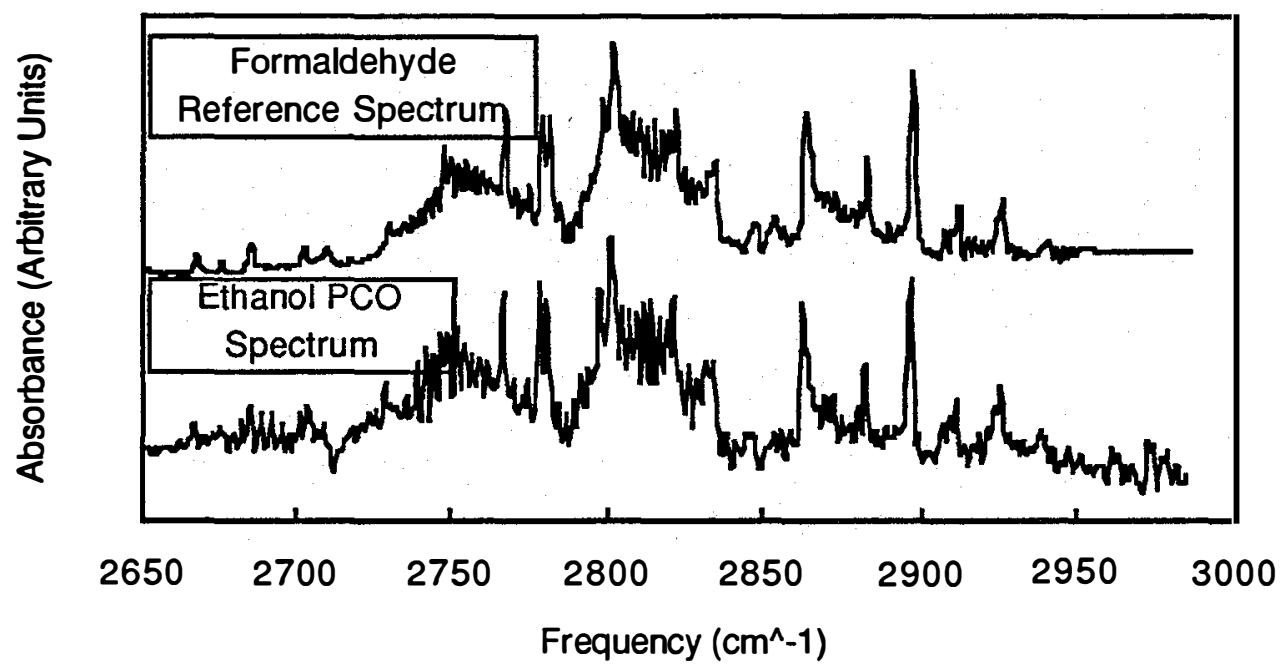

Figure 3.5 FTIR spectrum showing the formation of formaldehyde from ethanol

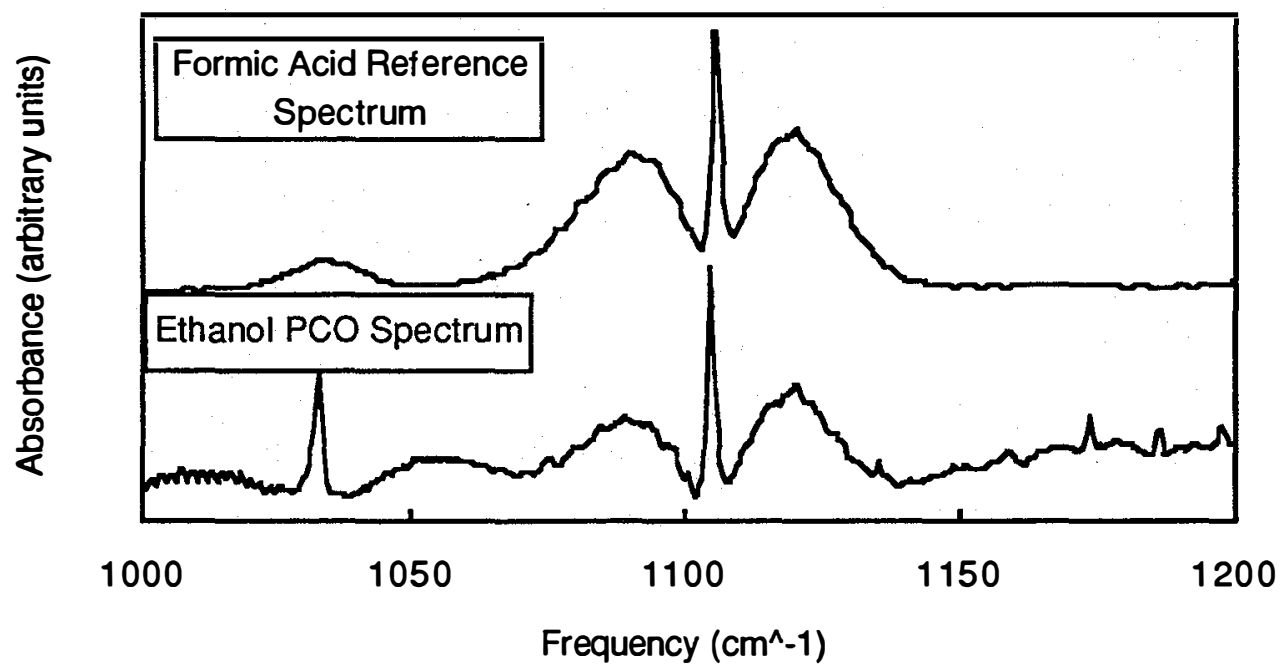

Figure 3.6 FTIR spectrum showing formic acid as product from ethanol

\subsection{Mechanisms}

We have suggested a chemical reaction mechanism to explain the observed reaction products from the photocatalytic oxidation of ethanol. This mechanism is outlined below and relies heavily upon chemical mechanisms suggested for homogeneous gas-phase reactions.

Studies of the photocatalytic oxidation of other alcohols has shown that 
aldehydes are formed from a dehydrogenation reaction and olefins are formed from a dehydration reaction[1,2]. We have not identified any ethylene (a dehydration product) during the photocatalytic oxidation of ethanol using FTIR spectroscopy. Thus, we think that dehydration is the major pathway for ethanol.

In our mechanism, the acetaldehyde is formed from the reaction of adsorbed ethanol with radicals (such as $\bullet \mathrm{OH}$ ) generated on the catalyst surface. The adsorbed acetaldehyde also reacts with radicals to form the acetate radical (3.7 to 3.9). This can either form acetic acid (3.10) or split to form $\mathrm{CO}_{2}$ and methyl radical. This reaction is similar to the Photo-Kolbe reaction which has been known to occur on illuminated $\mathrm{TiO}_{2}$ surfaces [3]. The methyl radical can further oxidize to form formaldehyde, formic acid and eventually carbon dioxide. The mechanism outlined below lists the individual reaction steps. The underlined molecules have been identified.

Dehydrogenation

$$
\begin{aligned}
& \underline{\mathrm{CH}_{3} \mathrm{CH}_{2} \mathrm{OH}}+\bullet \mathrm{OH} \rightarrow \mathrm{CH}_{3} \cdot \mathrm{CHOH}\left(\mathrm{CH}_{3} \mathrm{CH}_{2} \mathrm{O} \bullet\right)+\mathrm{H}_{2} \mathrm{O} \\
& \mathrm{CH}_{3} \cdot \mathrm{CHOH}+\mathrm{O}_{2} \rightarrow \underline{\mathrm{CH}_{3}} \underline{\mathrm{CHO}}+\mathrm{HOO} \bullet \\
& \underline{\mathrm{CH}_{3} \mathrm{CHO}}+\cdot \mathrm{OH} \rightarrow \mathrm{CH}_{3} \cdot \mathrm{CO}+\mathrm{H}_{2} \mathrm{O} \\
& \mathrm{CH}_{3} \bullet \mathrm{CO}+\mathrm{O}_{2} \rightarrow \mathrm{CH}_{3} \mathrm{C}(\mathrm{O}) \mathrm{OO} \bullet \\
& 2 \mathrm{CH}_{3} \mathrm{C}(\mathrm{O}) \mathrm{OO} \bullet-\rightarrow 2 \mathrm{CH}_{3} \mathrm{C}(\mathrm{O}) \mathrm{O} \bullet+\mathrm{O}_{2} \\
& \mathrm{CH}_{3} \mathrm{C}(\mathrm{O}) \mathrm{O} \bullet+\mathrm{RH} \rightarrow \underline{\mathrm{CH}_{3} \mathrm{C}(\mathrm{O}) \mathrm{OH}}+\mathrm{R} \bullet \\
& \mathrm{CH}_{3} \mathrm{C}(\mathrm{O}) \mathrm{O} \cdot \rightarrow \cdot \mathrm{CH}_{3}+\underline{\mathrm{CO}_{2}} \\
& \cdot \mathrm{CH}_{3}+\mathrm{O}_{2} \rightarrow \mathrm{CH}_{3} \mathrm{OO} \bullet \\
& 2 \mathrm{CH}_{3} \mathrm{OO} \cdot \longrightarrow 2 \mathrm{CH}_{3} \mathrm{O} \cdot+\mathrm{O}_{2} \\
& \mathrm{CH}_{3} \mathrm{O} \bullet+\mathrm{O}_{2} \rightarrow \underline{\mathrm{CH}_{2} \mathrm{O}}+\mathrm{HOO} \bullet \\
& \underline{\mathrm{CH}_{2} \mathrm{O}}+\cdot \mathrm{OH} \rightarrow \cdot \mathrm{CHO}+\mathrm{H}_{2} \mathrm{O} \\
& \cdot \mathrm{CHO}+\mathrm{O}_{2} \rightarrow \cdot \mathrm{OOCHO} \\
& 2 \cdot \mathrm{OOCHO} \rightarrow 2 \cdot \mathrm{OCHO}+\mathrm{O}_{2} \\
& \cdot \mathrm{OCHO}+\mathrm{RH} \rightarrow \underline{\mathrm{HCO}_{2} \mathrm{H}}+\mathrm{R} \bullet \\
& \underline{\mathrm{HCO}_{2} \mathrm{H}} \rightarrow \underline{\mathrm{CO}_{2}}
\end{aligned}
$$




\subsection{Conclusions}

A recirculating reactor has been successfully used to measure the photocatalytic oxidation of ethanol. Using a gas chromatograph and a gas phase FTIR, the products from this process have been measured. Four products were identified: acetaldehyde, formaldehyde, formic acid and carbon dioxide. The organic intermediates were found to be destroyed during the photocatalytic process, leaving only carbon dioxide at the end of a run (this was confirmed by complete carbon closures). The data from these experiments will be used for modeling studies (Chapter 4).

\subsection{References for Chapter Three}

1. Peral, J., and Ollis, D. F. "Heterogeneous photocatalytic oxidation of gas-phase organics for air purification: acetone, 1-butanol, butyraldehyde, formaldehyde, and m-xylene oxidation." J. Catal. 136, no. 2 (1992): 554-65.

2. Ait Ichou, I., Formenti, M., and Teichner, S. J. "Reverse spillowver of hydrogen adsorbed species in dehydrogenation photocatalysis on platinum-titania catalysts." Stud. Surf. Sci. Catal. 17 (1983): 63-75.

3. Sato, S. "Photo-Kolbe Reaction at Gas-Solid Interfaces." J. Phys. Chem. 87 (1983)3531-3537. 


\subsection{Modeling Ethanol}

\subsection{Introduction}

Gas-phase heterogeneous photocatalysis is an effective tool for the oxidation of many organic pollutants. Preliminary experiments performed at NREL have demonstrated the technology to effectively destroy such compounds as trichloroethylene; benzene/toluene/ethylbenzene/xylene mixtures (BTEX); and methyl-ethyl ketone (MEK), as well as ethanol. The purpose of this report is to summarize the work done to date on the development of a robust kinetic model of gas-phase photocatalysis. Ethanol is chosen as a model compound because there products are well characterized and the accurate kinetic measurements have been measured.

\subsection{Experimental}

Experiments were performed at the Solar Industrial Mesa Test Area (SIMTA) using a recirculating batch photocatalytic reactor assembly designed by NREL researchers. A schematic diagram of this apparatus is shown in Figure 3.1. The reactor assembly consists of a large (22-L) reservoir, a vacuum pump, and a tubular reactor. The actual photocatalytic reactor employed was a series of four $75-\mathrm{cm}-$ long 3/8-in (outside diameter) pyrex tubes with an inner coating of $\mathrm{TiO}_{2}$ (Degussa P25, anatase form). Illumination was supplied by a bank of four 48" fluorescent (black light) lamps mounted 18 in. above the reactor section. UV radiometry indicated an illumination intensity of $2.0 \mu \mathrm{W} / \mathrm{cm}^{2}$ at the reactor section. Analyses were performed with a portable gas chromatograph (MTI Model 20) equipped with two GC column/thermal conductivity detector assemblies in parallel.

In a standard run, the reactor assembly was first evacuated by exhausting the vacuum pump to the atmosphere. Typically, a vacuum greater than 15 in. $(\mathrm{Hg})$ could be obtained in this manner. After holding the system at vacuum for approximately 5 minutes, the vacuum pump was switched off and the assembly was refilled with room air. The vacuum was then reapplied for another 5 minutes. Liquid reactant was then introduced with a microsyringe and the system was filled with high-purity compressed air. The mixture was recirculated through the assembly for several minutes with the reactor section bypassed. Once a repeatable reactant signal was measured with the GC, flow was introduced to the reactor section, which was then illuminated.

The preliminary data collected to date for both ethanol and acetaldehyde degradation are shown in Figures 4.1 and 4.2. The lines in these plots show the Langmuir-Hinshelwood fits to the data. Considerable scatter exists in the data, and not all experimental variables have been rigorously examined. For example, the effect of both variable light intensity and water vapor concentration on the kinetics of ethanol degradation are being examined. However, the data do support a number 
of conclusions, as discussed below. The only products of ethanol degradation seen were acetaldehyde and $\mathrm{CO}_{2}$. Acetaldehyde destruction produced only $\mathrm{CO}_{2}$. Early ethanol degradation experiments were not run for a sufficient amount of time, so less than complete ethanol conversion to $\mathrm{CO}_{2}$ was achieved. This was evidenced in later runs by greater than 100 percent mass balances on carbon. That is, for a given run, more $\mathrm{CO}_{2}$ was produced than was added to the reactor as ethanol.

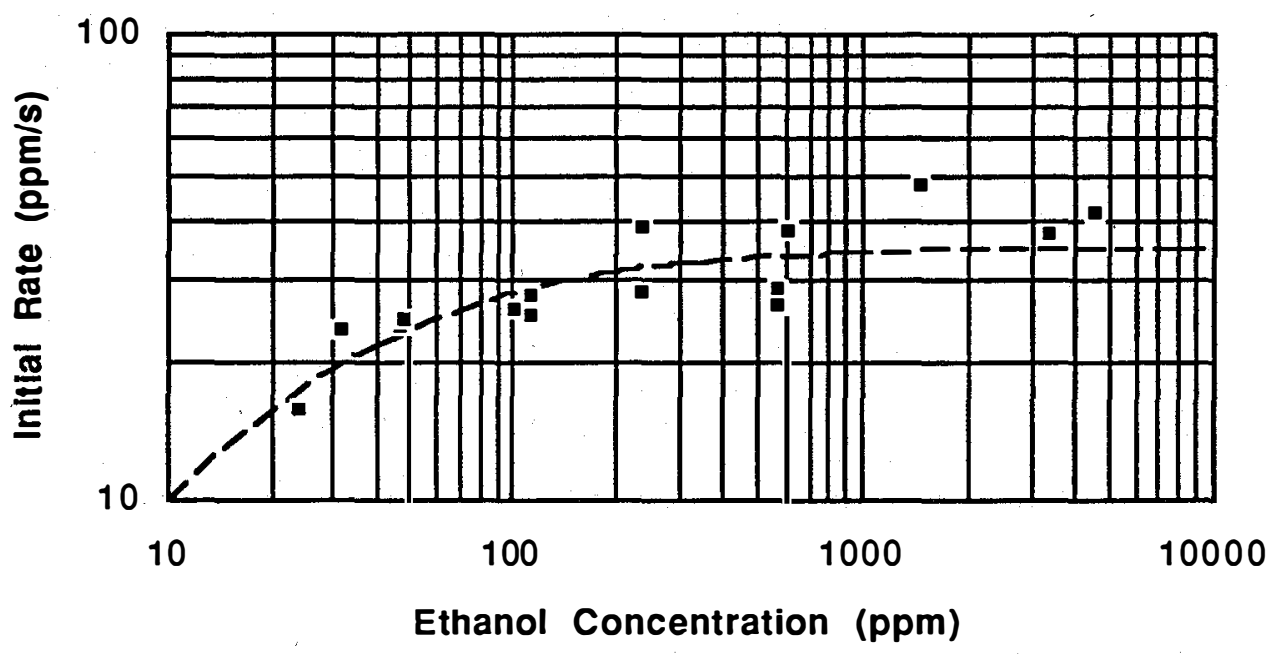

Figure 4.1 Initial rate data for ethanol photocatalytic destruction.

Significant scatter exists in the data. Solid line is rate expression calculated using parameter values from Table 4.1.

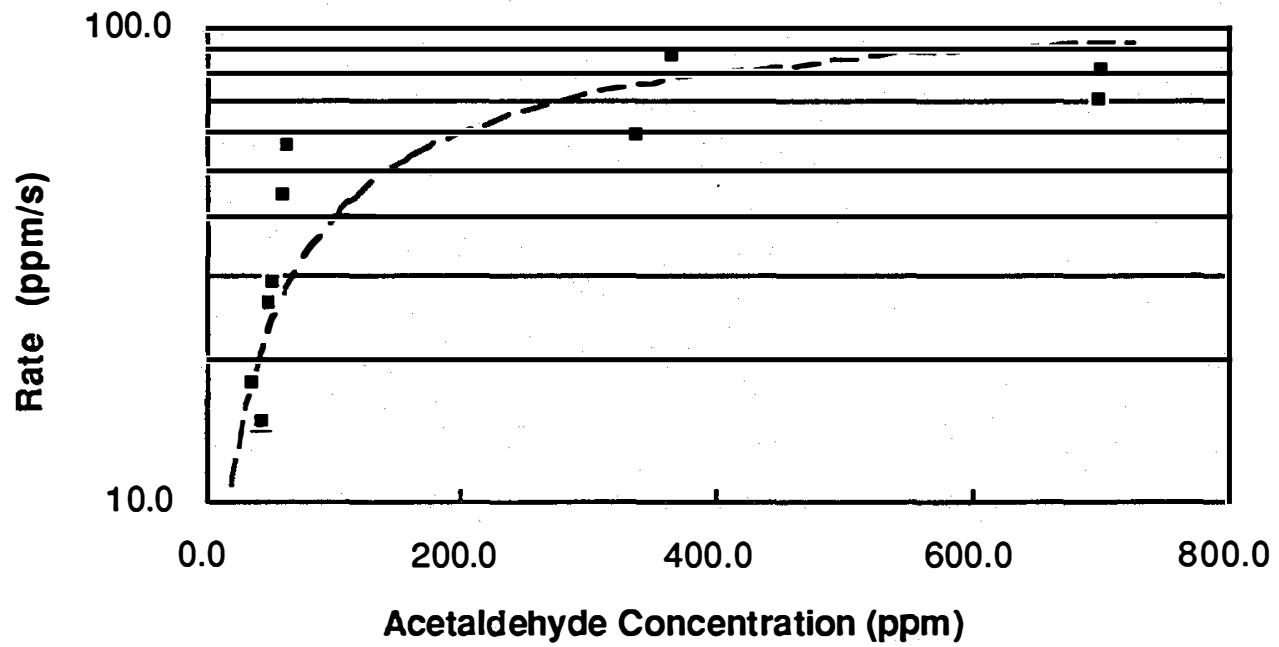

Figure 4.2 Initial rate data for acetaldehyde photocatalytic destruction Solid line is rate expression from inverse initial rate/inverse initial concentration plot. Dotted curve is rate expression using the parameter values from Table 4.1. 


\subsection{Model Development}

The experimental results of the gas-phase photocatalytic degradation of ethanol $\left(\mathrm{CH}_{3} \mathrm{CHOH}\right)$ clearly showed the production of acetaldehyde $\left(\mathrm{CH}_{3} \mathrm{CHO}\right)$ and carbon dioxide $\left(\mathrm{CO}_{2}\right)$ as products. Langmuir-Hinshelwood (L-H) kinetics are generally used in both gas- and the liquid-phase photocatalysis studies.

If one assumes the validity of the $\mathrm{L}-\mathrm{H}$ model with competitive adsorption by ethanol and acetaldehyde (but not by $\mathrm{CO}_{2}$ ), the controlling kinetic equations are as follows:

$$
\begin{aligned}
& \frac{d[E]}{d t}=\frac{-k_{E} K_{E}[E]}{1+K_{E}[E]+K_{A}[A]} \\
& \frac{d[A]}{d t}=\frac{k_{E} K_{E}[E]-k_{A} K_{A}[A]}{1+K_{E}[E]+K_{A}[A]} \\
& \frac{d\left[C O_{2}\right]}{d t}=\frac{2 k_{A} K_{A}[A]}{1+K_{E}[E]+K_{A}[A]}
\end{aligned}
$$

The possibility of another intermediate appearing after acetaldehyde but before $\mathrm{CO}_{2}$ was investigated. Eqs. 4.1-4.3 above were modified to include this second intermediate (S):

$$
\begin{aligned}
& \frac{d[E]}{d t}=\frac{-k_{E} K_{E}[E]}{1+K_{E}[E]+K_{A}[A]+K_{S}[S]} \\
& \frac{d[A]}{d t}=\frac{k_{E} K_{E}[E]-k_{A} K_{A}[A]}{1+K_{E}[E]+K_{A}[A]+K_{S}[S]} \\
& \frac{d[S]}{d t}=\frac{k_{A} K_{A}[A]-k_{S} K_{s}[S]}{1+K_{E}[E]+K_{A}[A]+K_{S}[S]} \\
& \frac{d\left[\mathrm{CO}_{2}\right]}{d t}=\frac{2 k_{S} K_{S}[S]}{1+K_{E}[E]+K_{A}[A]+K_{S}[S]}
\end{aligned}
$$

Implicit in Eqs. 4.6 and 4.7 is the fact that the intermediate $S$ contains two carbons. While this species has only recently been identified, this assumption is acceptable 
for the purposes of this analysis. These equations were solved numerically (in FORTRAN) using the fourth-order Runge-Kutta technique.

\subsection{Parameter Value Estimation}

This model requires two parameters each ( $k$ and $K$ ) for ethanol (E), acetaldehyde (A), and the second intermediate (S). The conventional method of parameter estimation in heterogeneous photocatalysis is to derive a linear transform of an assumed rate expression, and use linear curve-fitting techniques to determine parameter values. For the case of $\mathrm{L}-\mathrm{H}$ kinetics, a plot of the inverse initial rate vs. the inverse of the initial reactant concentration yields such a linear transform. Unfortunately, there is considerable scatter in the preliminary experiments performed to date (Figs. 4.1 and 4.2), particularly for ethanol destruction.

This linear transform technique was used to determine first estimates of the parameters $\mathrm{k}_{\mathrm{E}}, \mathrm{K}_{\mathrm{E}}, \mathrm{k}_{\mathrm{A}}$ and $\mathrm{K}_{\mathrm{A}}$, but the values were empirically adjusted to fit the temporal data. The relative values of $\mathrm{k}_{\mathrm{A}}$ and $\mathrm{k}_{\mathrm{E}}$ used in the modeling effort are approximately the same as the relative values of their respective second-order rate constants for reaction with the hydroxyl radical in the gas phase $\left(\mathrm{k}_{\mathrm{A}} / \mathrm{k}_{\mathrm{E}}=3.4\right.$ while $\left.\mathrm{kOH}_{\mathrm{A}} / \mathrm{K}_{\mathrm{E}}=5.5\right)$. For the two-intermediates-model, the binding and rate constants of the suspected intermediate were assumed to be roughly equal to that of acetaldehyde. They were then adjusted to fit the $\mathrm{CO}_{2}$ evolution. The values of the parameters used in the model are shown in Table 4.1:

Table 4.1 Parameter Values used in Gas-phase Photocatalysis Model

\begin{tabular}{||l|l|l||}
\hline \hline Compound & $\mathrm{k}\left(\mathrm{ppm} \mathrm{s}^{-1}\right)$ & $\mathrm{K}\left(\mathrm{ppm}^{-1}\right)$ \\
\hline Ethanol & 35 & 0.1 \\
\hline Acetaldehyde & 120 & 0.008 \\
\hline 2 $^{\text {nd Intermediate }}$ & 70.0 & 0.03 \\
\hline
\end{tabular}

\subsection{Model Results}

The results of this modeling effort are summarized in Figures 4.3 and 4.4. Using the single intermediate assumption, the temporal concentration profiles of both ethanol and acetaldehyde are well described by the model (Figure 4.3). However, the model predicts $\mathrm{CO}_{2}$ evolution to occur too quickly. This suggests that a second, undetected intermediate may exist. This intermediate would have adsorption properties similar to acetaldehyde, since if $\mathrm{K}_{\mathrm{S}}>>\mathrm{K}_{\mathrm{A}}$, significant inhibition of acetaldehyde destruction (not predicted by the model in Figure 4.3) would be seen. As a first approximation, the value of $\mathrm{K}_{\mathrm{S}}$ was set equal to $\mathrm{K}_{\mathrm{A}}$. It was 
then adjusted to fit the temporal data. The carbon balance in this reaction is displayed in Figure 4.5. The dotted line represents the calculated carbon balance using the calculated values of ethanol, acetaldehyde and carbon dioxide. As can be seen, the fit is reasonable.

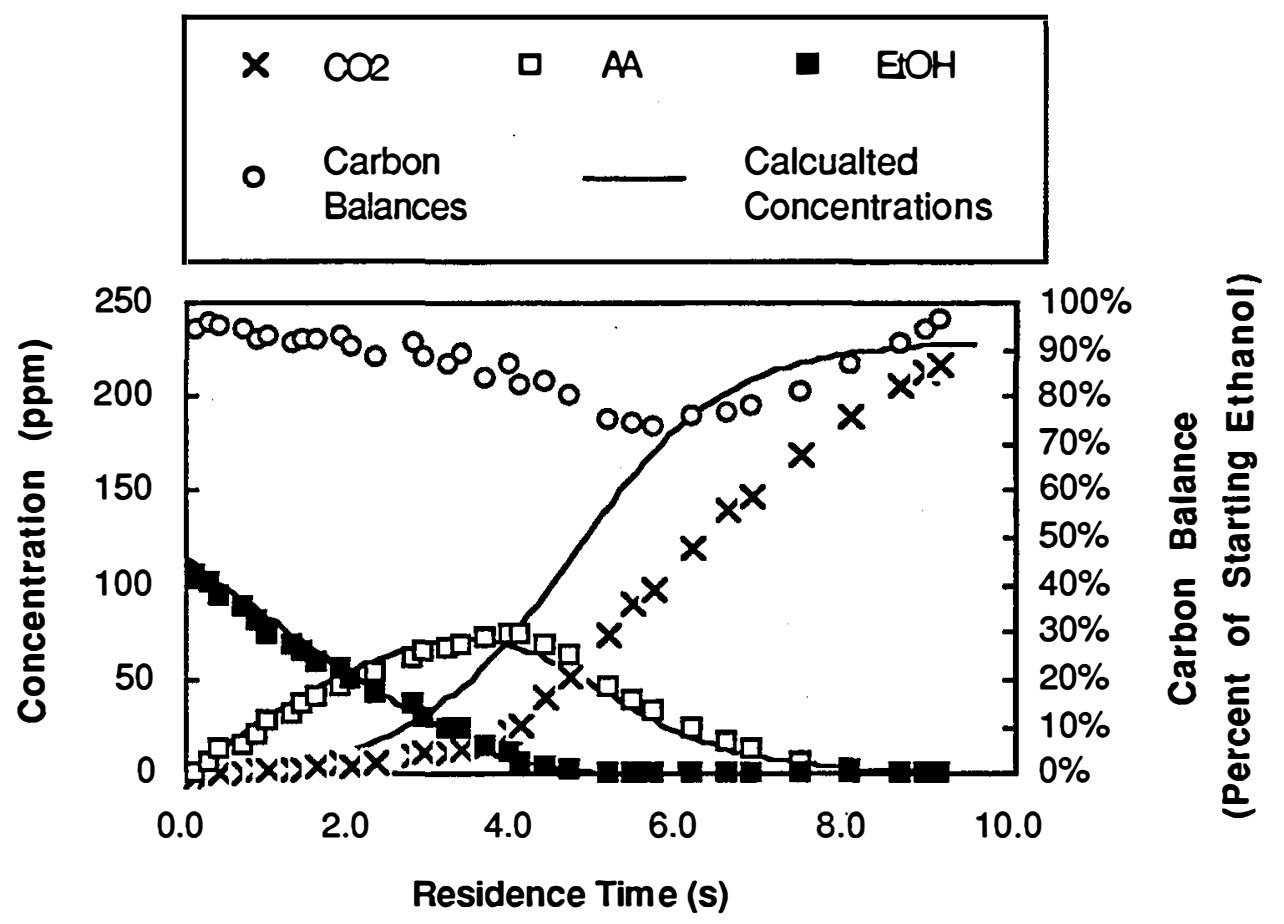

Figure 4.3 Results of modeling study using Eqs. 4.1-4.3 (single intermediate model) Both ethanol and acetaldehyde temporal concentration profiles are well described, but the model predicts too early a release of $\mathrm{CO}_{2}$ (see text).

The model parameters shown in Table 4.1 show that acetaldehyde apparently reacts more quickly than ethanol, but ethanol binds more strongly to the photocatalyst surface (a larger binding constant represents stronger surface affinity). This can be seen by examining the experimental data in Figure 4.3. Ethanol degradation readily gives acetaldehyde, but significant acetaldehyde degradation does not occur until the ethanol concentration drops to less than 10 percent of its original value. Acetaldehyde cannot effectively compete for surface sites with ethanol $\left(\mathrm{K}_{\mathrm{E}} / \mathrm{K}_{\mathrm{A}}=17.3\right)$ so only when ethanol is almost completely destroyed can acetaldehyde adsorb at the catalyst surface in significant quantities. Thus, the rate of photocatalytic degradation depends on both reactivity and adsorption.

One can use the values of the model parameters $\mathrm{kS}_{\mathrm{S}}$ and $\mathrm{K}_{\mathrm{S}}$ to draw some conclusions about the properties of the suspected intermediate $\mathrm{S}$. It was suspected that the intermediate may be acetic acid $\left(\mathrm{CH}_{3} \mathrm{COOH}\right)$, since after several weeks of use the catalyst-coated tubes had a distinctive vinegar odor. However, the results of this modeling effort suggest that the intermediate's binding constant (and therefore its 
adsorption properties) 'must be similar to acetaldehyde, and its reactivity must be greater than that of acetaldehyde. These observations effectively rule out acetic acid as the intermediate, because it should have adsorption properties similar to ethanol, and its reactivity, as measured by the value of its second order hydroxyl radical rate constant, is two orders of magnitude lower than for acetaldehyde. As mentioned in Chapter 3, formaldehyde was later identified as an intermediate using FTIR spectroscopy. This compound would have similar kinetic parameters as acetaldehyde.

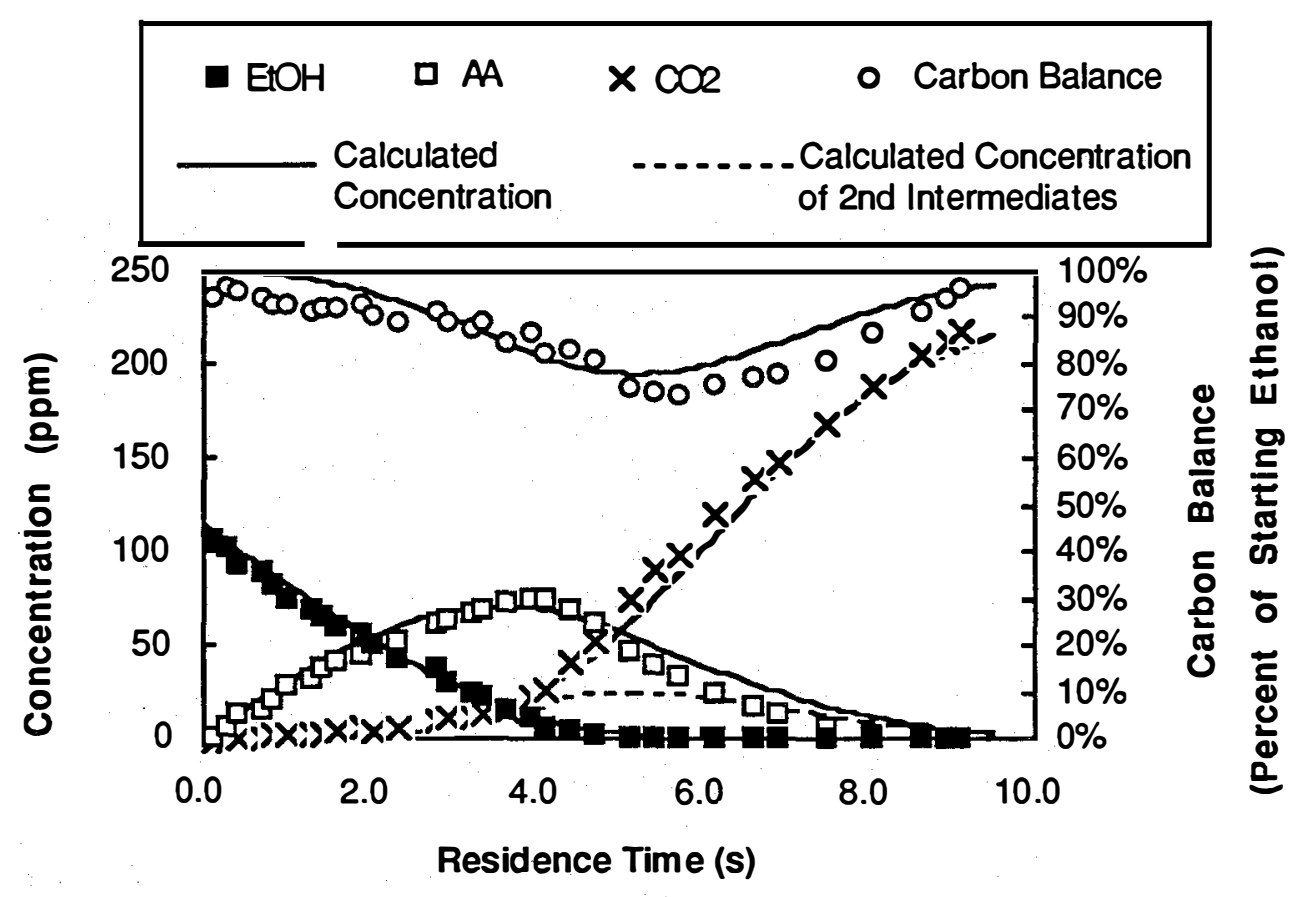

Figure 4.4 Results of modeling study using Eqs. 4-7 (two intermediates model) Addition of a second intermediate (as yet unidentified) improves agreement with experimental $\mathrm{CO}_{2}$ evolution data (see text).

\subsection{Conclusions}

An improved kinetic model has been developed that takes into account the production of intermediate species during the photocatalytic oxidation of ethanol to carbon dioxide. Preliminary results suggest that both adsorption on the photocatalyst surface and reactivity must be considered when evaluating the rate of photocatalytic destruction of a particular species. The preliminary modeling results also suggest the existence of another intermediate besides acetaldehyde, the identity of which is tentatively assigned as formaldehyde. 


\subsection{Recommendations for Future Work}

Since gas-phase photocatalysis is of industrial interest as a total oxidation technique, it is critically important to determine and identify the existence of the suspected intermediate compound S. More careful and exact laboratory experiments are currently underway at NREL.

A critical examination of the model parameter values in Table 4.1 is also necessary. The binding constants may be determined by performing dark adsorption studies. More careful experiments should produce much higher quality data than that shown in Figures 4.1 and 4.2, so the Langmuir-Hinshelwood rate formalism may yet yield good estimates for $\mathrm{k}_{\mathrm{E}}, \mathrm{K}_{\mathrm{E}}, \mathrm{k}_{\mathrm{A}}$, and $\mathrm{K}_{\mathrm{A}}$. These experiments are currently being carried out using a gas chromatograph with a more sensitive detector.

More laboratory experiments are necessary to determine the effect of such variables as water vapor concentration, illumination wavelength and intensity, and catalyst loading. Once these experiments are complete, a more rigorous (and therefore more useful) kinetic model, extendable to other organic species, should be within reach. 


\subsection{Field Tests at Coors Brewery}

\subsection{Introduction}

Because of the amendments to the Clean Air Act, a number of industries that were previously unregulated are being regulated for their air emissions. The Coors Brewery in Golden, Colorado is a facility that, because of its size, is being regulated for fugitive emissions of ethanol. In a study conducted by Coors in 1993, it was found that Coors exceeded its emissions limit (100 tons per year) by a factor of 15 . The company was subsequently fined $\$ 1.05$ million by the Colorado Department of Health. Many of the emissions from the Coors plant arise from high-volume/lowconcentration sources. These kinds of product streams are difficult to treat with conventional control technologies.

Photocatalytic oxidation has great promise as a technology that would be capable of treating the ethanol emissions from the facility. As mentioned in Chapter 3, PCO has been demonstrated on a laboratory scale for the complete destruction of ethanol. PCO also works well for low concentrations and low pressure drop/high-flow PCO systems can be built.

\subsection{Experimental}

For these reasons, NREL researchers conducted a series of field experiments at Coors on May 21 and 26, 1993 to evaluate PCO using a realistic waste stream. The site that was chosen for these tests was the waste treatment area on the north side of Route 58 west of McIntyre Road. Several rectangular holding pits there held beer-laden waste water prior to biological treatment. A blower assembly had been installed by Coors employees to strip ethanol from one of these pits. A sidestream was pulled off the blower to fill the reactor assembly. Since this air stream was off a stripper, it was saturated with water vapor (100percent $\mathrm{RH}$ ). The concentration of ethanol in the air stream varied with time, since the waste water contents was not constant. A continuous TOC monitor installed by Coors measured the blower exhaust stream approximately every 5 minutes. On one occasion, this monitor clearly indicated a large increase in TOC shortly after several thousand gallons of beer were sent to the waste treatment plant after failing some sort of quality check.

The recirculating batch reactor apparatus shown in Figure 3.2 was set up next to the waste water holding pit. Two $75-\mathrm{cm}$ coated tubes were used to collect data. Originally, four tubes were used, but the reaction proceeded too quickly to get good data. To start a run, a vacuum was pulled on the reactor system to remove any contaminants in the system. With the reactor section covered, the reservoir was backfilled with the ethanol-laden air from the blower assembly. This mixture was recirculated for several minutes until a repeatable ethanol signal was measured on the gas chromatograph (GC). Then the reactor section was uncovered, and GC 
samples taken as rapidly as possible.

The background $\mathrm{CO}_{2}$ levels in the stripper air stream were very high, apparently due to the respiration of aerobic bacteria in the wastewater. Because of this, $\mathrm{CO}_{2}$ produced by ethanol destruction could not be accurately monitored. Acetaldehyde production was not seen during these experiments. Because the water vapor concentration was very high, its corresponding GC area was large and it is likely that the water peak overwhelmed the acetaldehyde peak since in lab experiments the acetaldehyde peak shows up on the tail of the water peak.

\subsection{Results and Discussion}

The results of these field tests are presented in Table I below, as well as in Figure 1.

Table 5.1 Results of Tests at Coors Brewery: Summary of Field Tests Performed May 21 and 26.

\begin{tabular}{||c||c|c|c|c|c|c|c||}
\hline \hline Date & Run \# & $\begin{array}{c}{[\mathrm{E}]_{\mathrm{O}}} \\
(\mathrm{ppm})\end{array}$ & $\begin{array}{c}\mathrm{k}_{\mathrm{e}} \\
(\mathrm{ppm} / \mathrm{min})\end{array}$ & $\begin{array}{c}\mathrm{K}_{\mathrm{e}} \\
\left(\mathrm{ppm}^{-1}\right)\end{array}$ & Rate & $\begin{array}{c}\text { TUVR } \\
\left(\mathrm{W} / \mathrm{m}^{2}\right)\end{array}$ & $\begin{array}{c}\text { Quantum } \\
\text { Yield } \\
\text { (percent) }\end{array}$ \\
\hline \hline \multirow{6}{*}{ 26May } & 1 & 40.0 & 5.13 & .046 & 3.33 & 38.8 & 2.34 \\
\cline { 2 - 8 } & 2 & 20.4 & 7.57 & .036 & 4.46 & 46.5 & 2.61 \\
\cline { 2 - 8 } & 3 & 6.4 & 7.87 & .067 & 5.70 & 49.5 & 3.13 \\
\cline { 2 - 8 } & 4 & 12.7 & 5.59 & .102 & 4.48 & 51.4 & 2.37 \\
\cline { 2 - 8 } & 5 & 17.1 & 7.73 & .082 & 5.93 & 52.0 & 3.10 \\
\cline { 2 - 8 } & 6 & 14.8 & 16.9 & .037 & 10.1 & 51.1 & 5.36 \\
\hline \hline 21May & 1 & 32.4 & 8.78 & .020 & 3.89 & 45.0 & 2.35 \\
\cline { 2 - 8 } & 2 & 17.0 & 4.26 & .079 & 3.23 & 45.0 & 1.96 \\
\hline
\end{tabular}

The Langmuir-Hinshelwood constants shown in Table $5.1\left(\mathrm{k}_{\mathrm{e}}\right.$ and $\left.\mathrm{K}_{\mathrm{e}}\right)$ were calculated from a nonlinear curve-fit of each run. For ease of comparison, the rate data for each run presented in the table was extrapolated to a theoretical initial concentration of $40 \mathrm{ppm}$. The quantum yield was calculated as the ratio of initial rate to the product of exposed surface area and incident intensity. The intensity (TUVR) data $\left(\mathrm{W} / \mathrm{m}^{2}\right)$ was converted to Einsteins by assuming all photons had wavelength $366 \mathrm{~nm}$ ( 1 Einstein $=3.27 \times 10^{5} \mathrm{~J}$ ), and the rate data was converted from ppm to moles by dividing by $10^{6}$ (ppm to mole fraction) and then multiplying by the number of moles in the system.

The TUVR data was taken from the Solar Radiation Research Laboratory (SRRL) database for May 26, and was curve-fit with both Gaussian and Lorentzian functions (Figure 5.2). The cloud events that occurred after 11 a.m. on May 26 at 
SERL did not affect the Coors site: we noticed the contrast between Coors and SERL that day. The TUVR data for May 21 was estimated from the May 26 data.
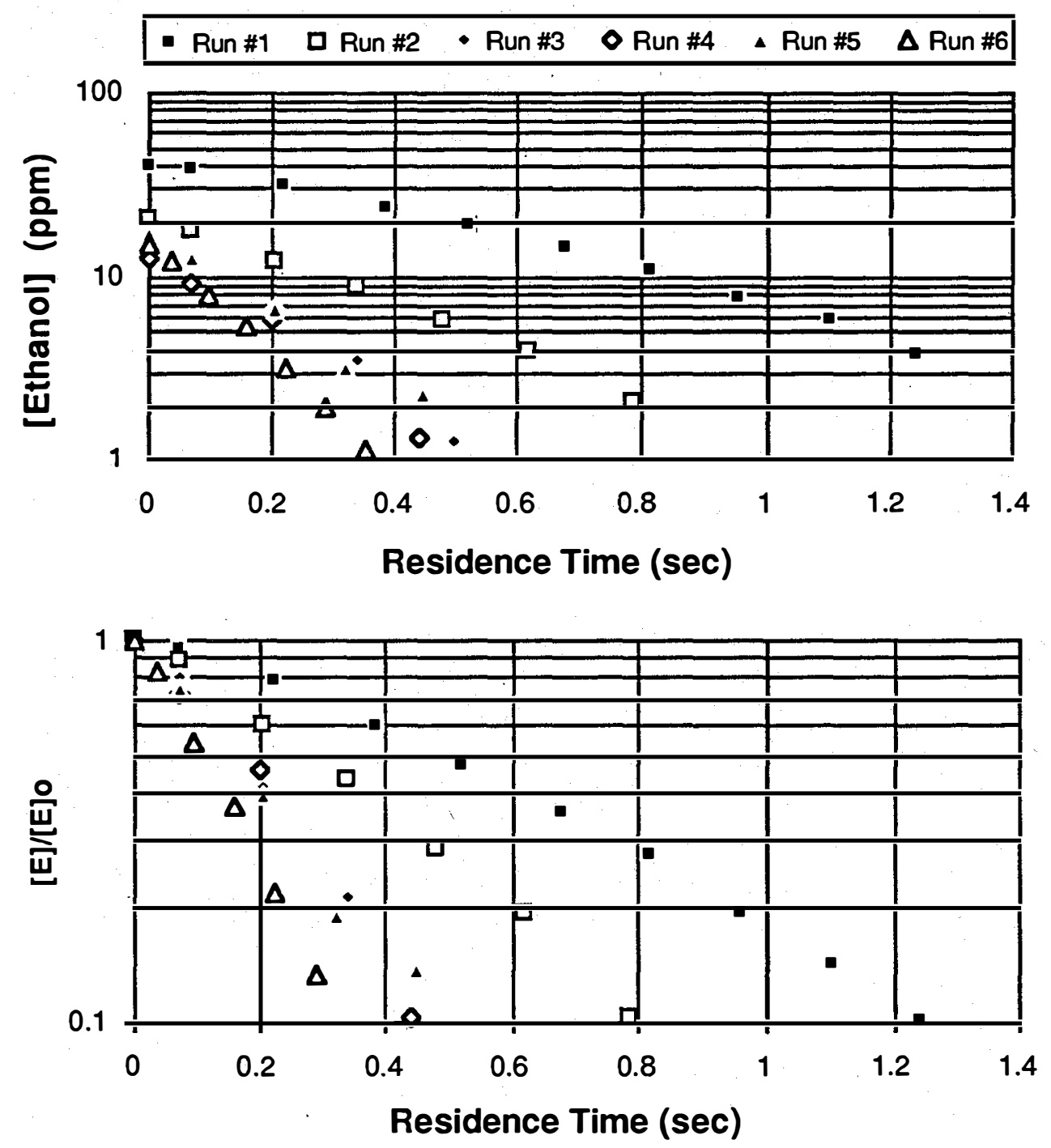

Figure 5.1 Results of tests of PCO at Coors on May 26, 1993

The correlation between predicted rate and incident intensity is reasonably good. With the exception of Run 6 of May 26, the standard deviation of the I values was 16 percent. The absolute values of these quantum yields $\left(I_{a v g}=2.55\right.$ percent) is lower than we had anticipated. In the lab we see quantum yields closer to 10 percent. It's not clear why these values are so much lower, although the water vapor concentration for the Coors experiments was higher than that for the lab experiments. 
The quantum yield values are calculated based on the initial rate of ethanol degradation. As shown in the figures, the degradation rate increased slightly as time passed, indicative of L-H kinetics. The value of the ethanol binding constant was on the order of $0.06 \mathrm{ppm}^{-1}$, with considerable scatter in the individual runs (std dev $=45$ percent). The value of $\mathrm{K}_{e}$ used in the ethanol modeling (Chapter 4) was 0.22 $\mathrm{ppm}^{-1}$, over three times as large, although in the modeling work the possibility of competitive adsorption between water and ethanol was not investigated. Since the water vapor concentration in the Coors data is much higher than in the ethanol lab data, its effect may show up in the apparent values of $\mathrm{K}_{\mathrm{e}}$.

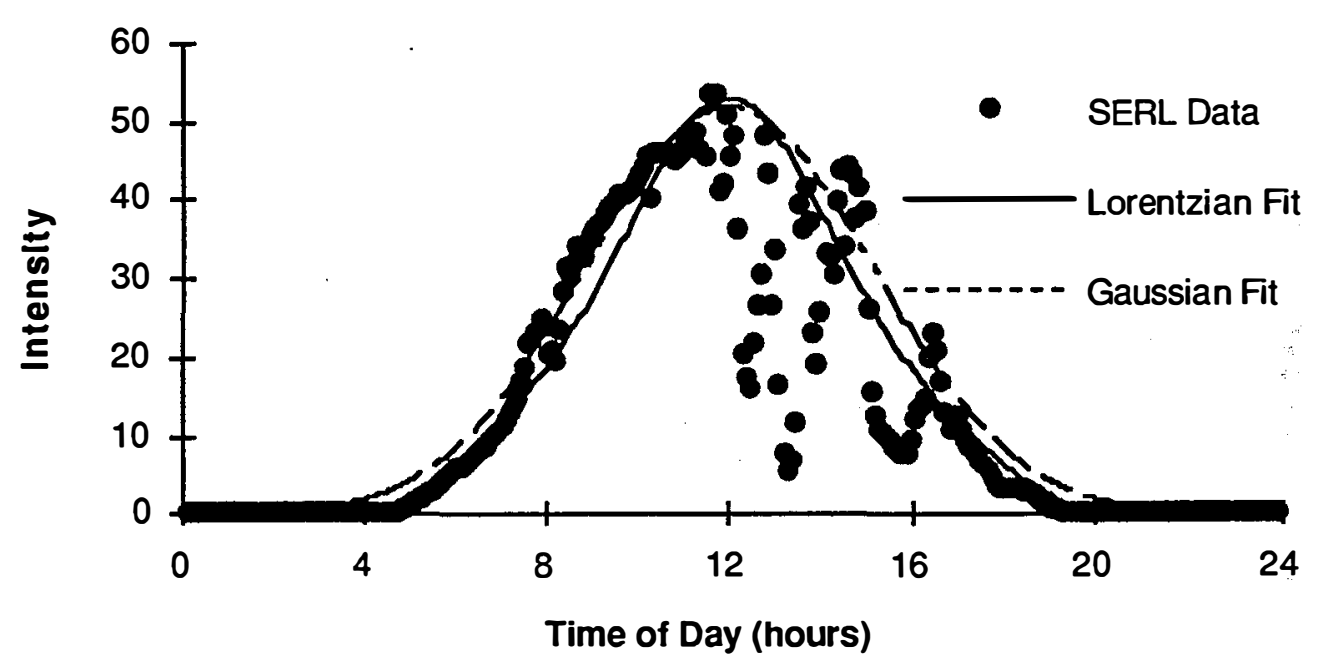

Figure 5.2 SERL data for May 26, 1993

\subsection{Conclusions}

Since the water vapor concentration was constant during each run, $\mathrm{K}_{\mathrm{e}}{ }^{*}$ would also be constant. The technology clearly works, although the lower than expected I values suggest that the effect of very high water vapor concentrations should be investigated in the lab. 


\subsection{Results from On-Site Tests at E/M Corporation}

\subsection{Introduction}

E/M Corporation is a subsidiary of Great Lakes Chemical Corporation and has ten to twenty plants throughout the United States with painting or coating operations. Much of the work is performed in paint booths, which are coming under increasing scrutiny from environmental regulatory agencies for their emissions of Volatile Organic Compounds (VOCs). Painting companies are in a difficult position because there are no approved technologies for controlling their emissions. (One option available to them is switching to nonvolatile solvents; however, this is expensive and often produces an inferior product.) Thus, E/M Corp. is interested in testing technologies such as photocatalytic destruction to controlits emissions.

The level of VOC destruction required by $\mathrm{E} / \mathrm{M}$ is unclear. The company is tightly regulated by the local air quality management district to not increase its emissions above the current daily total. This means that if $\mathrm{E} / \mathrm{M}$ needs to add another booth it must reduce the total emissions so there is no net gain in emissions. On top of this, the company will probably be required to reduce its total plant emissions over a period of years. Ray Krishock (their environmental compliance engineer), indicated that a reduction of 70 percent would probably be sufficient.

\subsection{Experimental}

During the week of July 28, 1993, tests of photocatalytic destruction were conducted at E/M's North Hollywood plant. At this facility were two newlyinstalled paint booths with carbon adsorption beds. The beds were saturated so that a relatively steady concentration of VOCs was being emitted whether or not the booth was in use. This constant concentration of organics simplified the experiments relative to real operating conditions, when the levels of VOCs may change dramatically, depending upon hood usage.

The experimental setup for these tests was the recirculating reactor apparatus used in lab tests at the SIMTA (Figure 3.1). The gas from the 22-L reservoir is pumped through the reactor $\left(3 / 8 \mathrm{in}\right.$. tubes coated inside with $\left.\mathrm{TiO}_{2}\right)$ and back to the reservoir. The organics are measured (using a portable GC) as a function of time, and the effective residence time is determined by multiplying the real time by the ratio of the volume of the reactor to the volume of the reservoir.

In these tests, the reservoir was filled with air from the paint booth, then ozone, and then passed through the illuminated reactor. The GC measured the VOCs after the reservoir was filled with paint booth air. In all of these tests the only 
components measured were ethanol $(\mathrm{EtOH})$, toluene (Tol) and methyl ethyl ketone (MEK). The reservoir was then partially evacuated and filled with ozone and oxygen from the ozone generator. The VOC levels were measured using the GC and ozone levels were measured using an 3-cm. absorption cell. Then the reactor was exposed to sunlight and the reaction was followed as a function of time.

\subsection{Results and Discussion}

Figure 6.1 shows a plot of the results of a typical experiment. Table 6.1 tabulates the results of all 15 runs. The figure shows measured total VOC levels as a function of effective residence times. Concentrations were calibrated by injecting standards. In these plots, time $=0 \mathrm{~s}$ represents the time at which the reactor was exposed to sunlight. The table presents the starting ozone level, the ultraviolet light flux and the number of seconds of residence time required for 99 percent destruction of the starting organics.

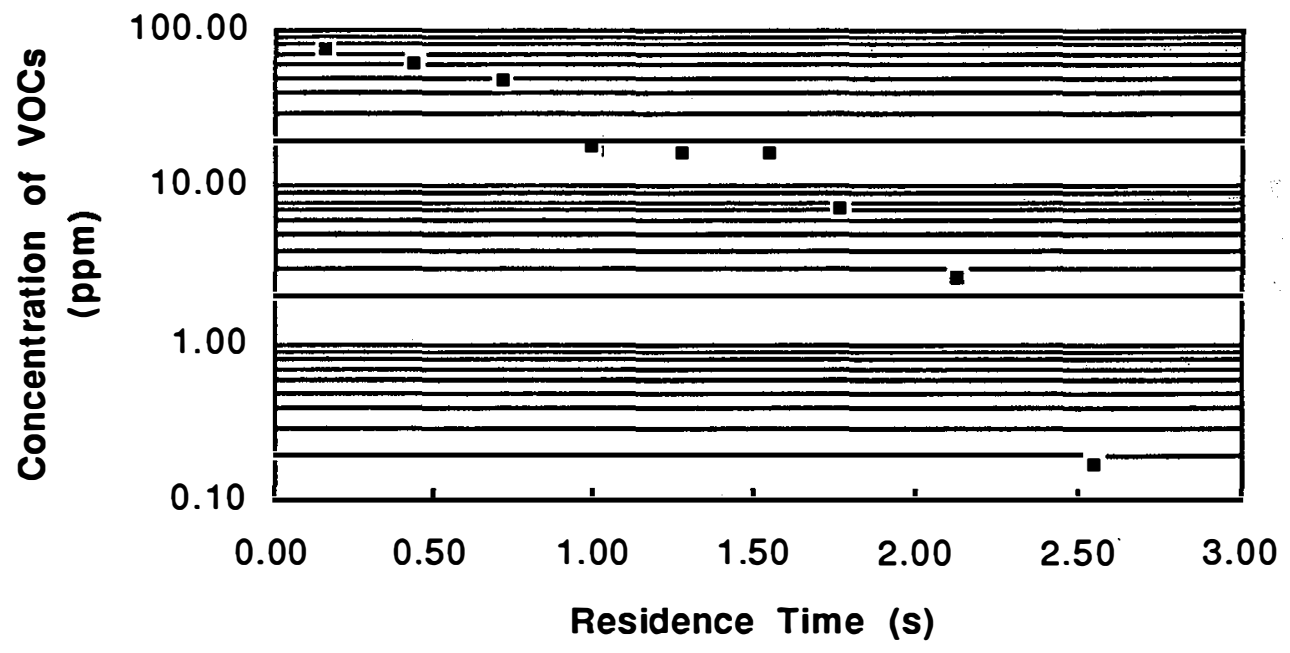

Figure 6.1 Results of Typical Experiment

During the first seven experiments, the measured level of total VOCs was between 250 and $350 \mathrm{ppm}$. After experiment number eight, when the ozone was added, there was a dramatic decrease in VOC levels. This decrease was greater than one would expect based upon dilution with the ozone/oxygen mixture. Furthermore, the decrease cannot be a result of the homogeneous reaction of ozone with the VOCs. But it may be a heterogeneous reaction. However, tests were conducted with the recirculating reactor which show that after the ozone has been added, VOC levels remain constant. After about the fifth run the starting VOC levels dropped in the absence of ozone until Run 8 , when essentially no VOCs were measured before the ozone was added. From Run 8 on, VOC levels were negligible until the ozone was added, at which point the VOC levels rose to a steady level. 
It is likely that the ozone somehow activates surfaces in the recirculating reactor for adsorption (i.e. the glass walls of the reservoir). When these low levels of VOCs are introduced, they adsorb to these activated surfaces. When the ozone is reintroduced the VOCs are displaced from the activated surfaces.

Table 6.1 Results of Experiments at E/M Corp.

\begin{tabular}{crrr}
\hline \hline Run & $\begin{array}{c}\text { Ozone } \\
\text { Concentration } \\
(\mathrm{ppm})\end{array}$ & $\begin{array}{c}\text { UV Flux } \\
\left(\mathrm{mW} / \mathrm{cm}^{2}\right)\end{array}$ & $\begin{array}{c}\text { Residence Time for } \\
\text { 99 Percent } \\
\text { Destruction of } \\
\text { VOCs }\end{array}$ \\
\hline 1 & 1639 & \multicolumn{2}{c}{3.14} \\
2 & 1696 & 2.39 & 3.53 \\
3 & 512 & 1.02 & 4.71 \\
4 & 630 & 1.74 & 6.67 \\
5 & 2491 & 1.57 & 2.75 \\
6 & 2625 & 1.83 & 2.55 \\
7 & 2123 & 2.16 & 4.41 \\
8 & 1836 & 2.09 & 3.66 \\
9 & 2945 & 1.26 & 2.41 \\
10 & 2390 & 1.54 & 2.16 \\
11 & 2020 & 1.81 & 2.05 \\
12 & 1613 & 1.94 & 1.32 \\
13 & 1766 & 2.02 & 1.79 \\
14 & 2059 & 1.9 & 1.99 \\
15 & 1029 & 1.55 & 2.55 \\
\hline \hline
\end{tabular}

Some general observations can be made.

1) When the mole fraction of the ozone was over $1000 \mathrm{ppm}$, the residence time required for about 99 percent destruction of the VOCs was about 3 to 4 seconds. The global quantum yield for this level of destruction was about 10 percent.

2) During the course of these tests, the intensities of some intermediate peaks rose. These intermediates have not been identified, but their intensities were significantly lower than the starting material peaks. The intermediates also reacted in the recirculating reactor and their complete destruction required about 1 to 2 seconds more residence time. It is not clear if these intermediates resulted from a photocatalytic reaction or if they resulted from a reaction with some part of the recirculating reactor with the ozone. 


\subsection{Future Tests}

Future laboratory tests are planned to resolve some important questions. Foremost is the question of what is happening to the VOCs upon introduction of ozone. To answer this, tests with a single-pass reactor will be conducted and the recirculating reactor will be modified so there can be no possibility of surface activation upon introduction of ozone. To accomplish this, the apparatus will be reconstructed using Teflon-coated parts.

In addition, more explicit quantification of the enhancement upon the introduction of ozone will be attempted. The kinetics for a simple compound such as benzene or toluene will be measured and an optimum concentration of ozone will be determined. The recirculating reactor will be used for these experiments if the strange results seen in this study can be avoided. Otherwise, we will use the single-pass reactor.

Finally, the chemical mechanism that accounts for the enhancement due to the addition of ozone will be determined, and intermediates will be confirmed and identified. 


\subsection{Rate Enhancement by the Addition of Oxidants}

\subsection{Introduction}

Contamination of soil and groundwater with fuel components is a major problem in the United States and other countries. Much of this contamination results from leaks in underground storage tanks at automobile filling stations, which make them the most common remediation sites in the country. The mixture of benzene, toluene, ethylbenzene and xylene (BTEX) is a major component of this fuel contamination. Moreover, benzene is a toxic compound and potential carcinogen. This makes the problem even more crucial.

A common process used to treat BTEX-contaminated soil and water is to strip out the organics and release them into the air. These processes take advantage of the volatility of BTEX and its immisciblity in water. For contaminated soil, the BTEX is removed by pulling a vacuum on the soil (commonly called a Soil Vapor Extraction, SVE, system), while for water BTEX is stripped by bubbling air through. These two processes share the common attribute of transferring BTEX from contaminated areas into the air. The contaminants are often simply released into the atmosphere. Such air emissions are of increasing concern and are likely to come under tighter control in the future.

Unfortunately, few economical means are available to control air emissions BTEX remediation. The most common technologies include adsorption on activated carbon and catalytic incineration. The process of carbon adsorption only transfers the pollutant to a solid that often must be treated as a hazardous waste, increasing its ultimate disposal costs. Catalytic incineration involves expensive equipment costs, and because the concentrations of BTEX are low, combustion of large amounts of fuel is required. Furthermore, thermal destruction processes are often difficult to permit and require expensive monitoring equipment.

As was mentioned in Chapter 1, the rate of photocatalytic oxidation for most compounds is significantly lower than for trichloroethylene. Furthermore, there are a number of compounds, notably aromatics, that appear to show little or no reactivity and that may deactivate the catalyst surface. For these compounds, the photocatalytic process needs to be improved to increase reaction rates and prevent catalyst deactivation.

Towards this goal, studies have been initiated to investigate the effect of adding oxidants. The enhancement of aqueous-phase photocatalysis rates with the addition of oxidants such as hydrogen peroxide and ozone has been demonstrated. In the gas phase, some researchers have demonstrated increased rates with lamps capable of generating ozone. However, this effect has not been quantified. The following chapter will discuss work at NREL to demonstrate and quantify the enhancement resulting from the addition of oxidants. The specific application of 
this technology to the treatment of fuel spills containing BTEX will also be discussed.

\subsection{Preliminary Experiments: Demonstrating the Concept}

Table 7.1 Preliminary Results Showing PCO Enhancement with Ozone

Compound $\quad \begin{gathered}\text { Percent Destroyed w/o } \\ \text { Ozone }\end{gathered}$

Experiment With 2-Propanol

gas flow $=2 \mathrm{slm}$

\begin{tabular}{lll}
\hline $2-\mathrm{PrOH}$ & 39 & $>99.7$
\end{tabular}

Experiment With BTX

gas flow $=1 \mathrm{slm}$

\begin{tabular}{|c|c|c|}
\hline $\begin{array}{l}\text { Benzene } \\
\text { Toluene } \\
\text { Xylene } \\
\text { gas flow = } 2 \mathrm{slm}\end{array}$ & $\begin{array}{l}\text { deactivated } \\
\text { deactivated } \\
\text { deactivated }\end{array}$ & $\begin{array}{l}79 \\
95 \\
>99.7\end{array}$ \\
\hline $\begin{array}{l}\text { Benzene } \\
\text { Toluene } \\
\text { Xylene }\end{array}$ & $\begin{array}{l}\text { deactivated } \\
\text { deactivated } \\
\text { deactivated }\end{array}$ & $\begin{array}{l}63 \\
77 \\
92\end{array}$ \\
\hline
\end{tabular}

Experiment with 2-Propanol

gas flow $=2 \mathrm{slm}$

\begin{tabular}{lll}
\hline 2-PrOH & $\begin{array}{l}0 \text { (deactivated from earlier } \\
\text { tests) }\end{array}$ \\
gas flow $=4 \mathrm{slm}$ & 099 \\
\hline 2-PrOH & 0 & 95 \\
\hline \hline
\end{tabular}

To demonstrate rate enhancement with oxidant, a series of screening experiments were conducted to determine the effect of adding ozone. These experiments were conducted using the molecular beam mass spectrometer (MBMS) and an single-pass annular reactor with black light illumination. Ozone was produced externally using an ozone generation system for hot tubs and introduced into the organic-spiked air upstream of the reactor. For these preliminary experiments, equipment was not available to monitor or control the ozone concentration. Table 7.1 shows the results from these preliminary tests. In the first experiment, the destruction of 2-propanol was increased by more than two orders of magnitude. In the second tests using a mixture of benzene, toluene and xylene, the catalyst deactivated without ozone, but high levels of destruction were obtained in the presence of ozone. In the third test with 2-propanol, the catalyst was deactivated from the BTX runs and no destruction was seen in the absence of ozone. However, 
with ozone the catalyst was reactivated and high levels of destruction of 2-propanol were seen.

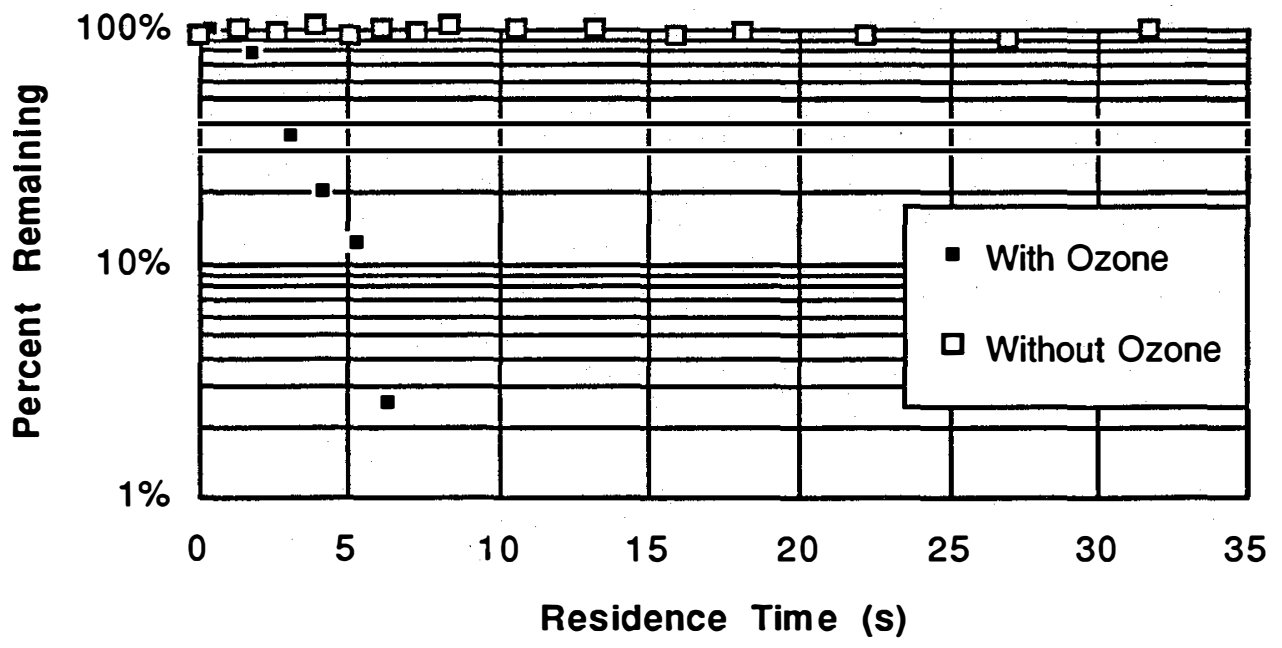

Figure 7.1 Destruction of toluene with and without ozone

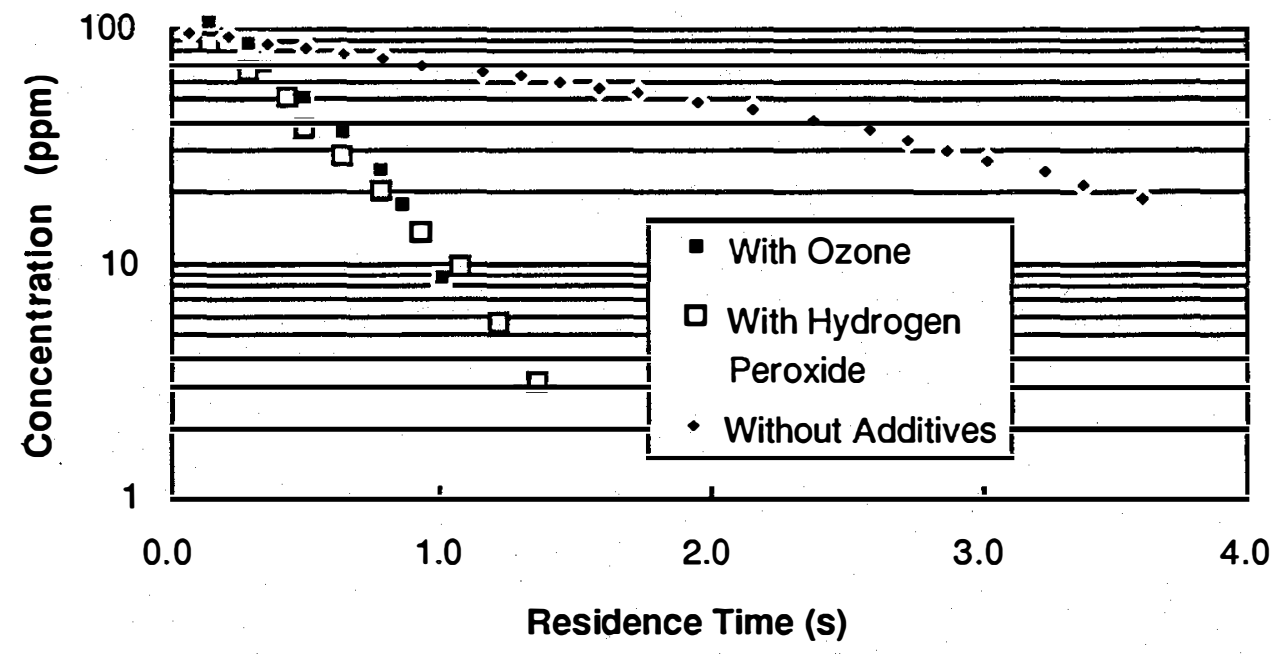

Figure 7.2 Enhancement of ethanol destruction with the addition of oxidants

Subsequent screening experiments using the MBMS found high levels of destruction of number two fuel oil and dichlorobenzene with PCO in the presence of ozone. These pollutants are important soil contaminants and previous experiments with PCO have shown that they deactivate the catalyst. 
A final set of screening tests was conducted using a recirculating batch reactor similar to that shown in Figure 3.1. Figure 7.1 shows a plot of toluene destruction in a recirculating batch reactor with and without the addition of ozone. As the figure shows, the rate of reaction of toluene dramatically increases when ozone is added. Figure 7.2 shows a plot of the destruction of ethanol in the recirculating reactor without additives and with the addition of ozone or hydrogen peroxide. In both cases, the enhancement was greater than an order of magnitude.

\subsection{Laboratory Research: Recirculating Reactor}

Initial attempts to measure the kinetics of PCO in the presence of ozone were conducted in the laboratory using a recirculating batch reactor similar to that shown in Figure 3.1. Air was spiked with the organic and ozone was recirculated through a series of tubular reactors (3/8-in. pyrex tubes with a thin coating of $\mathrm{TiO}_{2}$ on inside surface). The reactants and products were monitored using a portable GC (MTI) and the concentration of the ozone was followed using an absorption cell. This cell was an aluminum tube with a 254-nm light source on one side and a detector on the other. The concentration of ozone was determined using Beer's Law comparing transmittance with and without ozone.

The first set of experiments using the recirculating reactor were conducted to measure reactions in the absence of light and catalyst. These experiments were conducted using mixtures of benzene and ozone and ozone alone. The results of these experiments are presented in Figure 7.3. They show plots of these control experiments with the top plot showing the removal of benzene when a gas mixture of benzene/ozone bypasses the reactor and when the gas is recirculated through an unilluminated reactor. There is some decrease in the benzene, but it is small compared to the photocatalytic destruction rate. These results were confirmed using a single pass reactor on the MBMS, where it was found that there is a dark reaction involving the catalyst and ozone. This, however, is minimal. The bottom plot in Figure 7.4 shows the destruction of ozone in experiments with ozone alone. Again, small levels of ozone removal were seen.

These experiments illustrate the difficulty in conducting tests with the recirculating reactor. Because ozone is a strong oxidizer, dark reactions can be problematic. These reactions are probably not due to dark homogeneous reactions between ozone and benzene as the rate for this reaction is very slow[1]. It is more likely that surfaces in the recirculating loop outside of the reactor provide adsorption sites or reaction sites. Nonetheless, the recirculating reactor provided a convenient, simple way to obtain preliminary kinetic information. These results can be used to obtain rough cost estimates to determine future directions for this technology. 

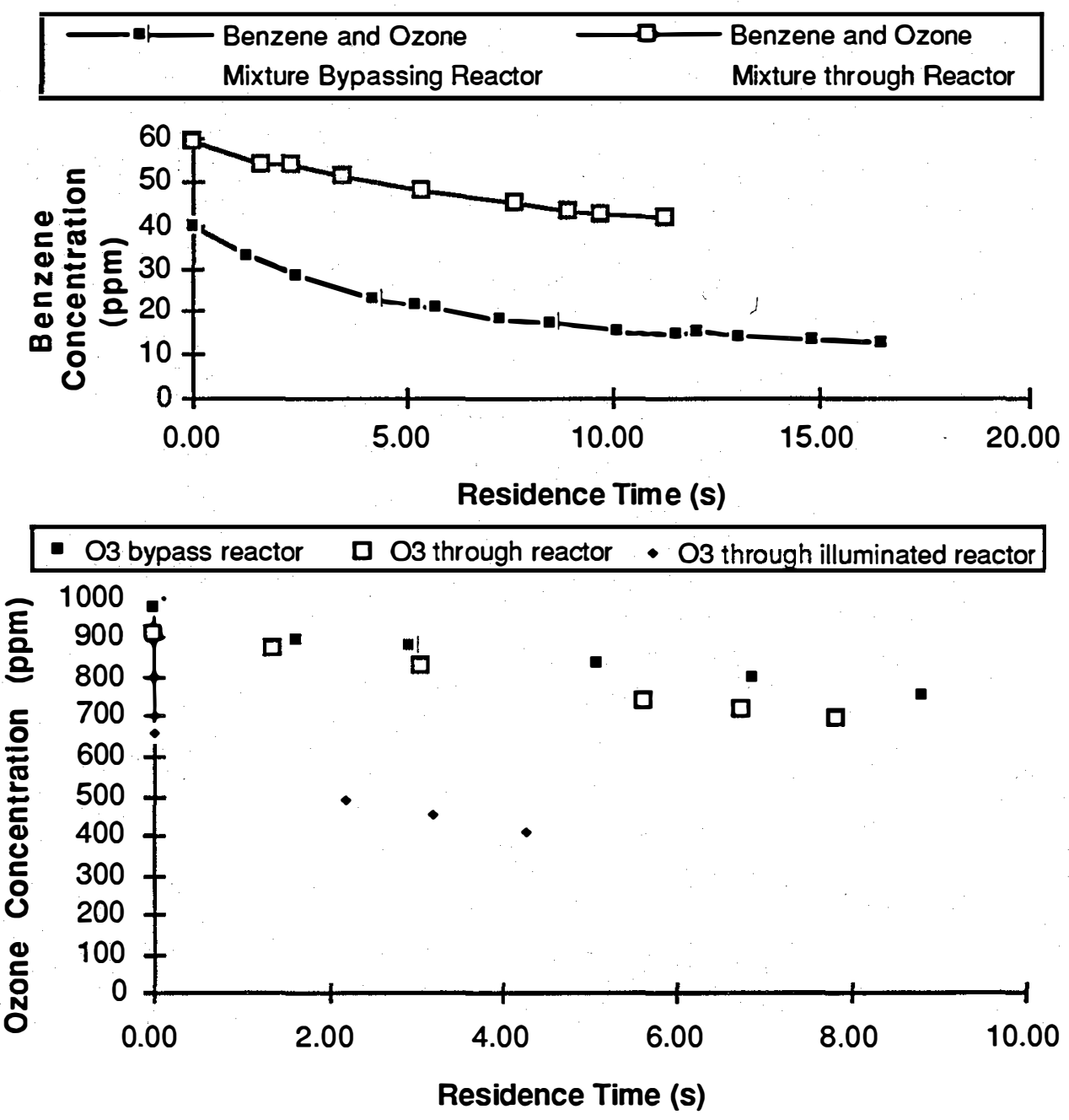

Figure 7.4 Results from control experiments with ozone and benzene (top) and ozone (bottom).

The first several PCO experiments involved either benzene and ethylbenzene destruction or toluene and p-xylene destruction separately. These data showed that rates of destruction follow molecular weight, with the xylenes exhibiting the fastest rates and benzene by far the slowest (xylenes>>ethylbenzene>toluene>>benzene). Subsequently, all additional experiments were performed using benzene only.

The experiments with benzene involved a starting concentration of approximately $100 \mathrm{ppmv}$, with parametric analysis of initial ozone and humidity concentrations. Three-point calibration with benzene was performed every day; this range bracketed the concentration found in the destruction studies. Table 7.2 shows the range of ozone concentrations which were studied, along with the residence time required for 99 percent destruction of the benzene and the quantum yield at 99 percent destruction. 
Table 7.2 Results from Recirculating Reactor Tests

\begin{tabular}{lcccc}
\hline \hline Date & $\begin{array}{c}\text { Benzene } \\
\text { Concentration } \\
(\mathrm{ppm})\end{array}$ & $\begin{array}{c}\text { Ozone } \\
\text { Concentration } \\
(\mathrm{ppm})\end{array}$ & $\begin{array}{c}\text { Residence } \\
\text { Time for 99 } \\
\text { percent DE }\end{array}$ & $\begin{array}{c}\text { Quantum Yield } \\
\text { for percent DE }\end{array}$ \\
\hline $8 / 23 / 93$ & 95 & 810 & 2.7 & $9.7 \%$ \\
$8 / 27 / 93$ & 96 & 1017 & 2.9 & $9.0 \%$ \\
$8 / 27 / 93$ & 97 & 731 & 3.4 & $7.8 \%$ \\
$9 / 1 / 93$ & 36 & 1053 & 1.4 & $7.0 \%$ \\
$9 / 1 / 93$ & 71 & 532 & 3.0 & $6.4 \%$ \\
$9 / 1 / 93$ & 52 & 983 & 1.9 & $8.6 \%$ \\
$9 / 2 / 93$ & 107 & 532 & 5.1 & $5.8 \%$ \\
$9 / 2 / 93$ & 69 & 928 & 3.0 & $6.3 \%$ \\
$9 / 3 / 93$ & 105 & 603 & 3.1 & $9.0 \%$ \\
$9 / 3 / 93$ & 83 & 879 & 2.4 & $9.3 \%$ \\
$9 / 9 / 93$ & 81 & 680 & 3.1 & $7.2 \%$ \\
$9 / 9 / 93$ & 88 & 510 & 3.8 & $6.4 \%$ \\
\hline \hline
\end{tabular}

* This is the relative humidity of the laboratory air. Final humidity in the reactor after dilution with ozone was not measured.

The results in general showed that the initial ozone concentration had a direct relationship to the time for destruction of benzene. However, as can be seen from the data in Table 7.2, there was a great deal of scatter in the results from this test. In general, it was difficult to reproduce the results from the recirculating reactor. It was likely due to the surfaces of the recirculating system outside of the reactor. Apparently these surfaces either provide reaction sites for dark reactions with the ozone, or the ozone activates surfaces for the adsorption of the organic. This activated adsorption is supported by the fact that after being filled with ozone, the measured concentration of benzene immediately after injection was often much lower than that which would be expected based upon material balances. In spite of these experimental difficulties, there was enough consistency in the data to conduct a preliminary cost analysis based upon a conservative estimate of the effectiveness of the process.

\subsection{System and Cost Analysis}

The size and cost of a PCO system necessary to treat the exhaust of a typical SVE was estimated using the measured rate data for pure benzene. For this analysis, the exhaust from the SVE contains $50 \mathrm{ppm}$ BTEX in an air flow of $750 \mathrm{ft} .3 / \mathrm{min}$. (This is the exhaust that was expected from the vacuum abstractor operated by SCS Engineers and is typical of SVEs.)

For this airflow, the size of a PCO system necessary for 99 percent destruction 
was estimated based upon a 5 second residence time and a 5 percent quantum yield. (These are conservative estimates of the measured values.) To treat this exhaust, a $30-\mathrm{kW}$ PCO system would be required. The reactor is assumed to be an annular reactor with black light fluorescence lamps as the inside of the annulus and 3-inch tubing as the outside of the annulus. Figure 6 shows a schematic diagram of a hypothetical PCO system. The amount of ozone used in this system is $500 \mathrm{ppm}$, a conservative estimate of what is necessary as determined from laboratory resutls.

To analyze the economic viability of this $\mathrm{PCO}$ system, a cost comparison was made between the PCO system and the two other technologies mentioned, carbon adsorption and catalytic incineration. This comparison was made with the help of Merick Engineers and Architects. Merck followed an EPA method for estimating the cost of the conventional technologies. The cost estimates for the PCO system were made based upon the individual components shown in Figure 7.5. The photoreactor costs were based upon the cost of a $30-\mathrm{kW}$ system from Matrix Photocatalytic. This cost should be high, because Matrix Photocatalytic uses a specially coated support that is unnecessary.

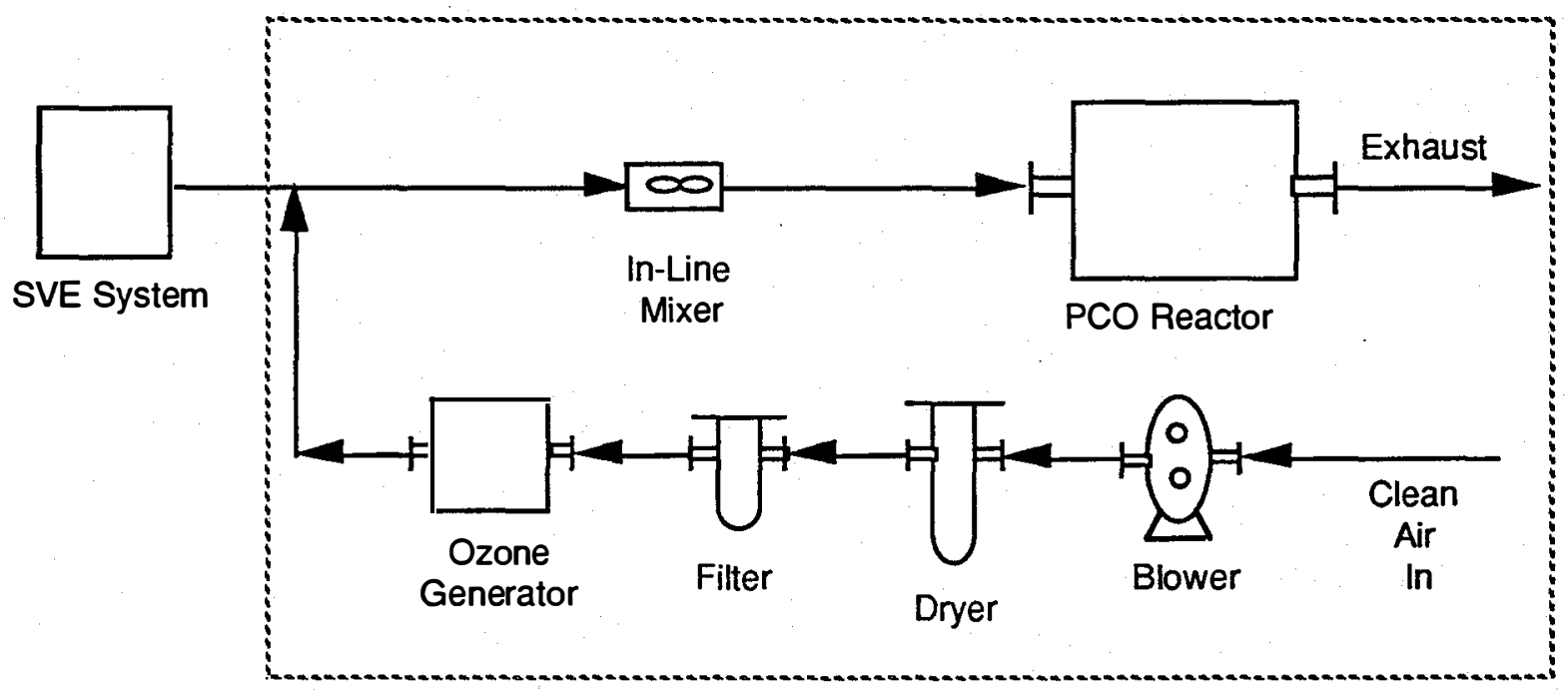

Figure 7.5 Schematic representation of hypothetical ozone/PCO system for cost analysis

A breakdown of the costs for these three systems is shown in the appendix. These costs are for capital equipment plus operating costs for a year. The cost were:

$\$ 243,407$ for carbon adsorption

$\$ 229,297$ for catalytic incineration $\$ 302,800$ for PCO

These preliminary figures indicate that $\mathrm{PCO}$ may be cost-competitive with the other technologies. The capital costs for the PCO system and the catalytic incineration and were much higher than for carbon adsorption although the 
operating costs for PCO and catalytic incineration were much lower than for carbon adsorption. This makes PCO attractive to waste remediation companies because they can amortize the capital costs over several years. Furthermore, the fact that PCO operates at ambient temperatures should make permitting easier than catalytic incineration.

\section{Table 7.3 Cost Comparison}

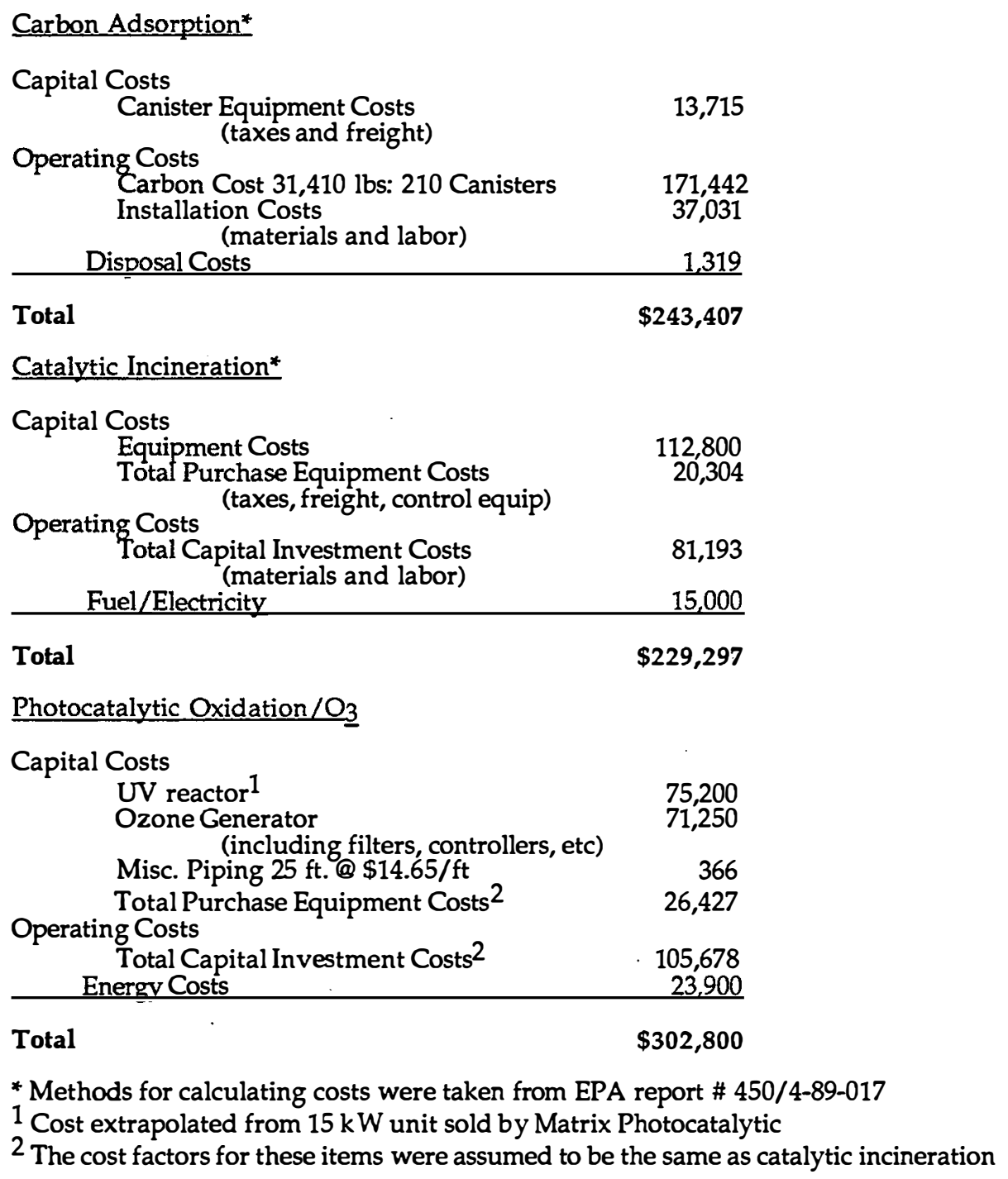

There are several factors which may help reduce the costs for PCO. The process was not optimized for the concentration of ozone needed. Since a conservative estimate was made, it is likely that a smaller amount of ozone would be needed. This could significantly lower the capital costs, energy costs and capital investment costs. Capital investment costs for PCO were estimated using the same factor as catalytic incineration. This factor should actually be lower for PCO, since PCO is conceptually simpler. Finally, the cost of the PCO reactor itself would be 
lower if less expensive materials were used.

\subsection{Single-Pass Experiments}

In order to collect more accurate kinetic data for the enhancement of PCO, new experiments use a single pass reactor setup. This setup uses an annular tube reactor and introduces the ozone (or hydrogen peroxide) immediately upstream of the reactor. The ozone level can be monitored before and after the reactor as can the organic concentration. Figures 7.6 and 7.7 show the results of some experiments with toluene. As can be seen, there does not appear to be as much scatter in the data as there was from the recirculating experiments, and these experiments should provide better kinetic data.

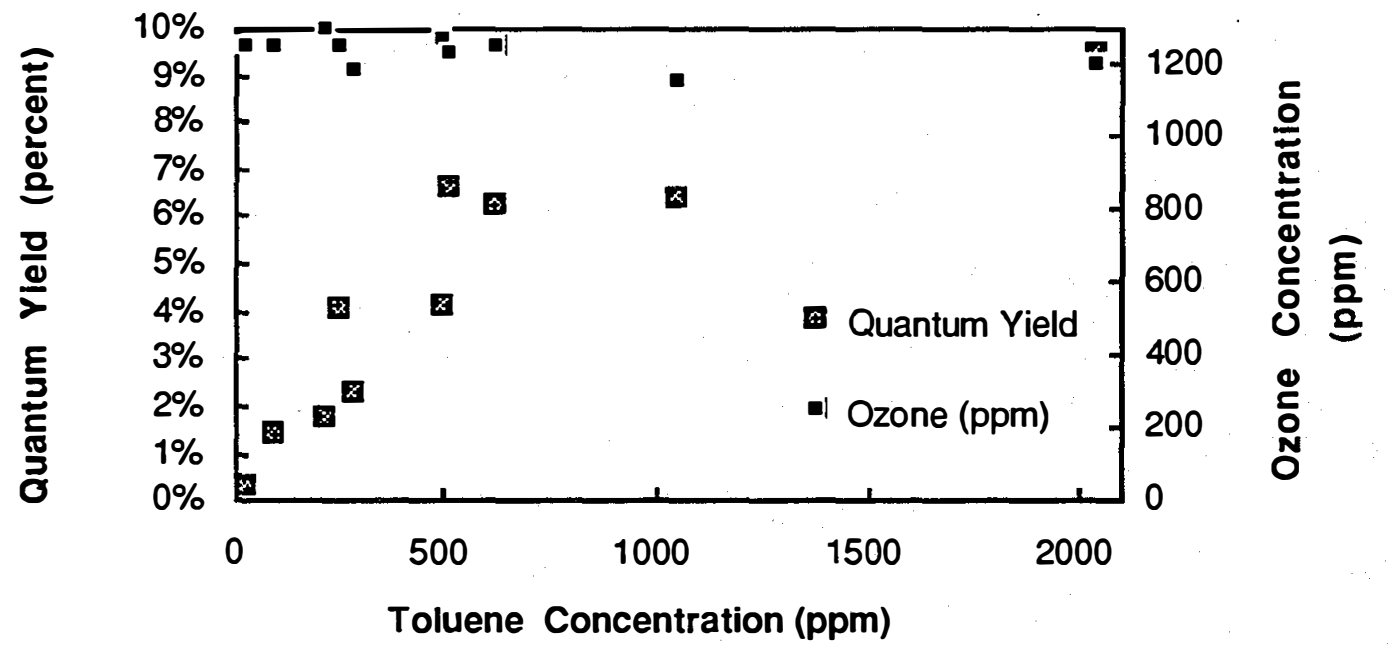

Figure 7.6 Photocatalytic destruction of toluene with the addition of ozone using single pass reactor

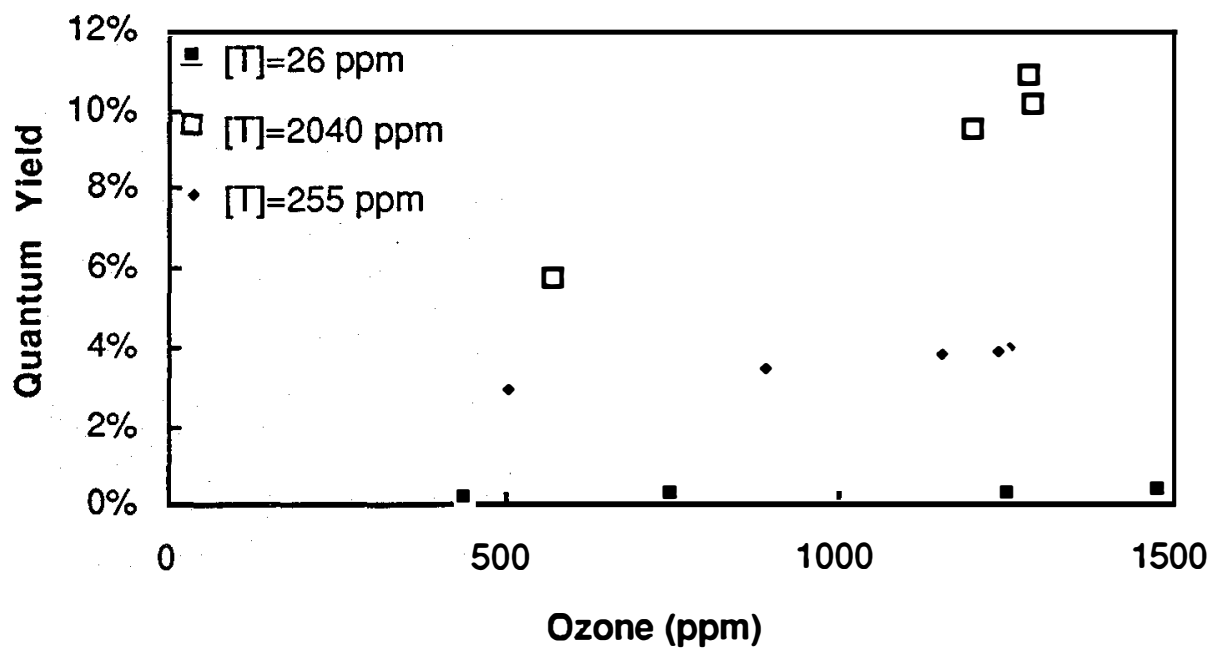

Figure 7.7 Quantum yields from the destruction of toluene from single pass reactor 


\subsection{Potential Markets}

To evaluate the potential for PCO as a waste destruction technology an informal study of the market was conducted. This study was based upon conversations with SCS Engineering, Merck Engineers and Architects and IT Corporation, and is by no means a complete survey. Because the addition of ozone has its largest impact upon aromatic compounds, only waste streams containing these compounds were considered.

\section{BTEX Sources}

As mentioned earlier, contamination of soil and groundwater from underground storage tanks (UST) is a major problem. There are an estimated two million commercial storage tanks in the United States, and roughly 60 percent of them have leaked and are in need of remediation. The current regulations on allowed emissions from vacuum abstractors depend upon state regulations. In Washington, for example, the allowed emissions are $15 \mathrm{lbs} /$ day, while in California the limit is $4 \mathrm{lbs} /$ day. It is likely that Washington's lax regulations will be tightened in the future. For the example considered above (50 ppm in $750 \mathrm{scfm}$ ), the Washington regulations would not require control while the California regulations would. It is likely that with the new Clean Air Act Amendments, future regulations will require controlling or elimination of emissions from remediation devices. It should also be mentioned that the Department of Defense has many UST's that have leaked, though the exact number is unknown. This could represent another potentially large market.

A number of other sources of BTEX emissions are associated with the petroleum industry. These include the following:

1) Refining BTEX sources

Crude and product storage tanks

Crude unit desalters

Slop oil tanks

2) Gasoline and crude transfer operations

3) Gasoline tank breathing

4) Gasoline station vent pipes

The exact number of these sites has not been determined, but PCO offers a potentially simple method to control their emissions.

\section{Paint Booths}

Paint booths present another potential use for this technology. The solvents used in many paints include toluene and xylenes. Currently, during painting and coating operations the solvents are removed from the work area and pumped into 
the atmosphere. However, stricter regulations required by the Clean Air Act may force businesses to control these emissions or switch to nonvolatile solvents. The available technologies for controlling these emissions (carbon adsorption and thermal destruction) are expensive and difficult to permit. The concentrations of solvents in these emissions are often very low (roughly $100 \mathrm{ppm}$ ), which makes this an ideal application for photocatalytic detoxification. E/M Corporation, which operates 20 to 30 coating plants, is very interested in developing this technology for use at their painting facilities and is willing to help with demonstrations.

\section{Chemical Industry}

There are a number of chemical operations which use aromatic solvents that could employ PCO to clean air or wastewater emissions. The PCO units could either be fitted onto the air exhausts from buildings or hoods or onto waste water air strippers.

\subsection{Conclusions}

Photocatalytic oxidation, with the addition of ozone, is a promising new technology for treating air streams containing aromatic compounds. The ozone dramatically increases the rate of destruction of the compounds (benzene and toluene) that are the most difficult to destroy using PCO without additives. Based upon laboratory rate data, the cost of a PCO control unit may be cost-competitive with other control technologies. Using the results of this study, MTNW and SCS Engineering are pursuing other sources of funding for pilot tests. Furthermore, NREL has signed a CRADA with IT Corporation to develop and commercialize PCO as a waste destruction technique. With these corporate interests, the prospects for PCO look promising. 


\section{Appendix: Reports of Gas-Phase Photocatalysis in the Literature}

\begin{tabular}{|c|c|c|c|}
\hline Compound & Formula & TRI & Reference \\
\hline \multicolumn{4}{|c|}{ Halogenated Compounds } \\
\hline 1,1,1-Trichloroethane & $\mathrm{CH}_{3} \mathrm{CCl}_{3}$ & 3,5 & 1 \\
\hline Trichloroethylene & $\mathrm{CHClCCl}_{2}$ & 1,5 & $\begin{array}{l}27,28,29,30,25,19,31 \\
32,1,20,33,34,35\end{array}$ \\
\hline Tetrachloroethylene & $\mathrm{CCl}_{2} \mathrm{CCl}_{2}$ & 1,5 & 25 \\
\hline 3,3,3-Trifluoropropene & $\mathrm{CH}_{2} \mathrm{CHCF}_{3}$ & 0 & 10 \\
\hline Carbon tetrabromide & $\mathrm{CBr} 4$ & 0 & 43 \\
\hline Chlorofluorocarbons, various & & 0 & $44,45,1,46,47,48$ \\
\hline Dichloroacetyl Chloride & $\mathrm{CHCl}_{2} \mathrm{CClO}$ & 0 & 19,20 \\
\hline 1,1-Difluoroethylene & $\mathrm{CH}_{2} \mathrm{CF}_{2}$ & 0 & 10 \\
\hline Tetrafluoroethylene & $\mathrm{C}_{2} \mathrm{~F}_{4}$ & 0 & 10 \\
\hline Chloroform & $\mathrm{CHCl}_{3}$ & 1 & 1 \\
\hline Phosgene & $\mathrm{CCl}_{2} \mathrm{O}$ & 2,5 & 19,20 \\
\hline \multicolumn{4}{|c|}{ Aliphatic Hydrocarbons } \\
\hline Butadiene & $\mathrm{CH}_{2} \mathrm{CHCHCH}_{2}$ & 5 & 2 \\
\hline 2,2,4-Trimethylpentane & $\left(\mathrm{CH}_{3}\right)_{3} \mathrm{C}_{5} \mathrm{H}_{9}$ & & 1 \\
\hline 1-Hexene & $\mathrm{CH}_{3}\left(\mathrm{CH}_{2}\right)_{5}$ & 0 & 36 \\
\hline Ethane & $\mathrm{C}_{2} \mathrm{H}_{6}$ & 0 & 49 \\
\hline Isobutane & $\mathrm{i}-\mathrm{C}_{4} \mathrm{H}_{10}$ & 0 & $2,21,50,51,22,52$ \\
\hline Propyne & $\mathrm{CH}_{3} \mathrm{CCH}$ & 0 & 2,50 \\
\hline Isoprene & $\mathrm{CH}_{2} \mathrm{C}\left(\mathrm{CH}_{3}\right) \mathrm{CHCH}_{2}$ & 0 & 53 \\
\hline Butadiene & $\mathrm{CH}_{2} \mathrm{CHCHCH}_{2}$ & 0 & 2 \\
\hline Ethylene & $\mathrm{CH}_{2} \mathrm{CH}_{2}$ & 5 & 2,10 \\
\hline Propene & $\mathrm{CH}_{3} \mathrm{CHCH}_{2}$ & 5 & $2,21,22,23$ \\
\hline \multicolumn{4}{|c|}{ Aromatic Hydrocarbons } \\
\hline Toluene & $\mathrm{C}_{6} \mathrm{H}_{5} \mathrm{CH}_{3}$ & 2,5 & $1,4,26$ \\
\hline Stilbene & $\mathrm{C}_{6} \mathrm{H}_{5} \mathrm{CHCHC}_{6} \mathrm{H}_{5}$ & 0 & 12 \\
\hline Xylenes & $\mathrm{C}_{6} \mathrm{H}_{4}\left(\mathrm{CH}_{3}\right)_{2}$ & 5 & 6 \\
\hline 4-tert-Butyltoluene & $p-\left(\mathrm{t}-\mathrm{C}_{4} \mathrm{H}_{9}\right) \mathrm{C}_{6} \mathrm{H}_{4} \mathrm{CH}_{3}$ & 0 & 37 \\
\hline Benzene & $\mathrm{C}_{6} \mathrm{H}_{6}$ & 1 & 8,1 \\
\hline \multicolumn{4}{|l|}{ Alcohols } \\
\hline tert-Butyl alcohol & $\left(\mathrm{CH}_{3}\right)_{3} \mathrm{COH}$ & 5 & 24 \\
\hline Isopropyl alcohol & $\left(\mathrm{CH}_{3}\right)_{2} \mathrm{CHOH}$ & 5 & $11,12,13,14$ \\
\hline 1-Butanol & $\mathrm{CH}_{3}\left(\mathrm{CH}_{2}\right)_{3} \mathrm{OH}$ & 0 & 9,6 \\
\hline Methanol & $\mathrm{CH}_{3} \mathrm{OH}$ & 4,5 & $15,16,17$ \\
\hline \multicolumn{4}{|c|}{ Aldehydes, Ketones and Ethers } \\
\hline Acetaldehyde & $\mathrm{CH}_{3} \mathrm{CO}$ & 5 & $3,4,5$ \\
\hline Acetone & $\mathrm{CH}_{3} \mathrm{COCH}_{3}$ & 2 & $1,6,7$ \\
\hline Butyraldehyde & $\mathrm{CH}_{3}\left(\mathrm{CH}_{2}\right)_{2} \mathrm{CHO}$ & 5 & 9,6 \\
\hline Formaldehyde & $\mathrm{CH}_{2} \mathrm{O}$ & 2,5 & 6 \\
\hline Methyl tert-butyl ether & $\left(\mathrm{CH}_{3}\right)_{3} \mathrm{COCH}_{3}$ & 5 & 18 \\
\hline
\end{tabular}




\begin{tabular}{llll}
\hline \multicolumn{1}{c}{ Others } & & & \\
\hline Dimethylformamide & $\mathrm{HCON}\left(\mathrm{CH}_{3}\right)_{2}$ & 3 & 1 \\
Carbon dioxide (reduction) & $\mathrm{CO}_{2}$ & 0 & $38,39,40$ \\
Carbon monoxide & $\mathrm{CO}$ & 0 & $12,41,19,42,40$ \\
Acetic acid & $\mathrm{CH}_{3} \mathrm{CO}_{2}$ & $?$ & 55 \\
Isobutyric acid & $\mathrm{CH}_{3} \mathrm{CH}_{\left(\mathrm{CH}_{3}\right) \mathrm{CO}_{2} \mathrm{H}}$ & 0 & 4,26 \\
Methanethiol & $\mathrm{CH}_{3} \mathrm{SH}$ & 0 & $54,4,26,5$ \\
Pyridine & $\mathrm{C}_{5} \mathrm{H}_{5} \mathrm{~N}$ & 0 & 40 \\
Trimethylamine & $\left(\mathrm{CH}_{3}\right)_{3} \mathrm{~N}$ & 0 & 5 \\
\hline
\end{tabular}




\section{References}

1. Lichtin, N. N., Dong, J., and Vijayakumar, K. M. "Photopromoted titanium oxide-catalyzed oxidative decomposition of organic pollutants in water and in the vapor phase." Water Pollut. Res. J. Can 27, no. 1 (1992): 203-10.

2. Anpo, M., Aikawa, N., and Kubokawa, Y. "Photocatalytic hydrogenation of alkynes and alkenes with water over $\mathrm{TiO}_{2}$. Pt-loading effect on the primary process." J. Phys. Chem. 88 (1984): 3998-4000.

3. Ikeda, T., Tokumitsu, S., Naruo, N., and Fukunaga, M. Deodorization by using photocatalysts. Jpn. Kokai Tokkyo Koho P. Japan Patent 01288321 A2. Japan Patent 88-117239, 13 May 1988. (20 November 1989).

4. Suzuki, K. I., Satoh, S., and Yoshida, T. "Photocatalytic deodorization on $\mathrm{TiO}_{2}$ coated honeycomb ceramics." Denki Kagaku 59, no. 6 (1991): 521-3.

5. Tokumitsu, S., Naruo, N., Fukunaga, M., and Ikeda, T. Deodorization using photocatalysts and apparatus for the deodorization. In Jpn. Kokai Tokkyo Koho P. Japan Patent 01159030 A2. Japan Patent 87-319413, 17 Dec 1987. (22 June 1989).

6. Peral, J., and Ollis, D. F. "Heterogeneous photocatalytic oxidation of gas-phase organics for air purification: acetone, 1-butanol, butyraldehyde, formaldehyde, and m-xylene oxidation." J. Catal. 136, no. 2 (1992): 554-65.

7. Barbeni, M., Pelizzetti, E., Borgarello, E., Serpone, N., Graetzel, M., Balducci, L., and Visca, M. "Hydrogen from hydrogen sulfide cleavage. Improved efficiencies via modification of semiconductor particulates." Int. J. Hydrogen Energy 10, no. 4 (1985): 249-53.

8. Isidorov, V. A., Klokova, E. M., Kozubenko, S. G., and Ivanova, A. R. "Photocatalytic destruction of aromatic hydrocarbons on the surface of natural aerosol components." Vestn. St. Peterb. Univ., Ser. 4: Fiz., Khim., no. 2 (1992): 97-100.

9. Blake, N. R., and Griffin, G. L. "Selectivity control during the photoassisted oxidation of 1-butanol on titanium dioxide." J. Phys. Chem. 92, no. 20 (1988): 5697-5701.

10. Ohtani, B., Ueda, Y., Nishimoto, S., Kagiya, T., and Hachisuka, H. "Photocatalytic oxidative decomposition of fluoroalkenes by titanium dioxide." J. Chem. Soc. Perkin Trans. 2 (1990): 1955-90.

11. Ait Ichou, I., Formenti, M., and Teichner, S. J. "Photocatalytic dehydrogenation of isopropanol on $\mathrm{Pt} / \mathrm{TiO}_{2}$ catalysts in connection with water photosplitting." Stud. Surf. Sci. Catal. 19 (1984): 297-307.

12. Ait Ichou, I., Formenti, M., Pommier, B., and Teichner, S. J. "Photocatalytic dehydrogenation of isopropanol on $\mathrm{Pt} / \mathrm{TiO}_{2}$ catalysts." J. Catal. 91, no. 2 (1985): 293-307.

13. Ait Ichou, I., Formenti, M., and Teichner, S. J. "Reverse spillowver of hydrogen adsorbed species in dehydrogenation photocatalysis on platinum-titania catalysts." Stud. Surf. Sci. Catal. 17 (1983): 63-75. 
14. Cunningham, J., Goold, E. L., Hodnett, B. K., Leahy, E. M., and Al Sayyed, G. "Photoassisted gas-solid reactions, photocatalytic processes and endergonic photoconversions over pure and surface-doped metal oxides." Stud. Surf. Sci. Catal. 19 (1984): 283-90.

15. Carlson, T., and Griffin, G. L. "Photooxidation of methanol using $\mathrm{V}_{2} \mathrm{O}_{5} / \mathrm{TiO}_{2}$ and $\mathrm{MoO} 3 / \mathrm{TiO}_{2}$ surface oxide monolayer catalysts." J. Phys. Chem. 90, no. 22 (1986): 5896-5900.

16. Liu, Y. C., Griffin, G. L., Chan, S. S., and Wachs, I. E. "Photo-oxidation of methanol using $\mathrm{MoO}_{3} / \mathrm{TiO}_{2}$ : catalyst structure and reaction selectivity." J. Catal. 94 (1985): 108-19.

17. Viswanathan, B., Mary, U. D., and Viswanath, R. P. "Photocatalytic dehydrogenation of methanol on platinum/titanium dioxide." Indian J. Chem., Sect. A: Inorg., Phys., Theor. Anal 29A, no. 11 (1990): 1138-9.

18. Raupp, G. B., Junio, C. T., Mallela, R. K., and Phillips, L. A. "Destruction of organics in gaseous streams over UV-excited titania." Air and Waste Management Association, Kansas City, Missouri, 21 June 1992.

19. Blake, D. M., Jacoby, W. A., Nimlos, M. R., and Noble, R. "Identification and quantification of by-products and intermediates in the photocatalytic oxidation of gas-phase trichloroethylene." 6th Proceedings of 6th Int. Symp. on Sol. Thermal Concentrating Tech., Mojacar, Spain, 28 September 1992: 1223-31.

20. Nimlos, M. R., Jacoby, W. A., Blake, D. M., and Milne, T. A. "Direct mass spectrometric studies of the destruction of hazardous wastes 2. Gas phase photocatalytic oxidation of trichloroethylene over $\mathrm{TiO}_{2}$ : products and mechanisms." Environ. Sci. Technol. 27 (1993): 732-40.

21. Anpo, M., Chiba, K., Tomonari, M., Coluccia, S., Che, M., and Fox, M. A. "Photocatalysis on native and platinum-loaded $\mathrm{TiO}_{2}$ and $\mathrm{Zno}$ catalysts - origin of different reactivities on wet and dry metal oxides." Bull. Chem. Soc. Jpn. 64 (1991): 543-51.

22. Courbon, A. F. ,. M., Juillet, F., Lisachenko, A. A., Martin, J., and Teichner, S. J. "Photocatalytic activity of nonporous titanium dioxide (anatase)." Kinet. Katal. 14, no. 1 (1973): 110-17.

23. Juillet, F., Teichner, S., and Formenti, M. "Photocatalytic oxidation of hydrocarbons," Great Britain Patent 1331084, 19 September 1973.

24. Walker, A., Formenti, M., Meriaudeau, P., and Teichner, S. J. "Heterogeneous photocatalysis: photooxidation of methylbutanols." J. Catal. 50, no. 2 (1977): 237-43.

25. Al-Ekabi, H., and Holden, W. "The photocatalytic destruction of gaseous trichloroethylene and tetrachloroethylene over immobilized titanium dioxide." Manuscript in Preparation (1992).

26. Suzuki, K. "Photocatalytic air purification on $\mathrm{TiO}_{2}$ coated honeycomb support." Proc. of the First Int. Conf. on $\mathrm{TiO}_{2}$ Photocatalytic Purification and Treatment of Water and Air, in Press. London, Ontario, 8 November 1992. 
27. Dibble, L. A., and Raupp, G. B. "Fluidized bed photocatalytic oxidation of trichloroethylene in contaminated air streams." Environ. Sci. Technol. 26, no. 3 (1993): 492-5.

28. Dibble, L. A., and Raupp, G. B. "Heterogeneous photocatalysis: A novel approach for the degradation of volatile organic water pollutants." Ariz. Hydrol. Soc. 1st Ann. Symp. "Survival in the Desert: Water Quality and Quantity Issues into the 21st Century," 221-229. Phoenix, Ariz., 16 September 1988.

29. Dibble, Lynette A., and Gregory B. Raupp. "Kinetics of the gas-solid heterogeneous photocatalytic oxidation of trichloroethylene by near UV illuminated titanium dioxide," private communication, September 1989.

30. Raupp, G. B., and Dibble, L. A. Gas-solid photocatalytic oxidation of environmental pollutants. In EP. WO 9104094 A1 W: CA, JP RW: AT, BE, CH, DE, DK, ES, FR, GB, IT, LU, NL, SE. WO 90-US4996, 4 Sep 1990. (4 April 1991).

31. Dibble, L. A. "Gas-solid heterogeneous photocatalytic oxidation of trichloroethylene by near-ultraviolet-illuminated titanium dioxide." Ph.D. diss., Arizona State Univ, 1989.

32. Dibble, L. A., and Raupp, G. B. "Kinetics of the gas-solid heterogeneous photocatalytic oxidation of trichloroethylene by near UV illuminated titanium dioxide." Catal. Lett. 4, no. 4-6 (1990): 345-54.

33. Bahnemann, D. W., Monig, J., and Chapman, R. "Efficient photocatalysis of the irreversible one-electron and two-electron reduction of haloethane on platinized colloidal titanium dioxide in aqueous suspension." J. Phys. Chem. 91 (1987): 3782-88.

34. Raupp, G. B., and Dibble, L. A. Gas-solid photocatalytic oxidation of environmental pollutants. U.S. Patent. 5,045,288. (3 September 1991).

35. Yamazaki-Nishida, S., Nagano, K. J., Phillips, L. A., Cervera-March, S., and Anderson, M. A. "Photocatalytic degradation of trichloroethylene in the gas phase using titanium dioxide pellets." J. Photochem. Photobiol., A 70, no. 1 (1993): 95-9.

36. Stepanenko, V. I., Lyashenko, L. V., and Belousov, V. M. "Heterogeneous and homogeneous photooxidation of hydrocarbons on titanium-containing catalysts." Khim. Fiz. 4, no. 1 (1985): 97-102.

37. Pichat, P., Courbon, H., Disdier, J., Mozzanega, M. N., and Herrmann, J. M. "Heterogeneous photocatalysis: nitric oxide decomposition and oxidation of butanols by nitric oxide over titanium dioxide at room temperature." Stud. Surf. Sci. Catal. 7, no. Pt. B, New Horiz. Catal (1981): 1498-1500.

38. Anpo, M., and Chiba, K. "Photocatalytic reduction of carbon dioxide on anchored titanium oxide catalysts." J. Mol. Catal. 74, no. 1-3 (1992): 207-12.

39. Halmann, M., and Aurian-Blajeni, B. CECED9. Semiconductor-electrolyte solar cells for the photoelectrochemical reduction of carbon dioxide to organic fuel, 1979.

40. Tanaka, K., and White, J. M. "Characterization of species adsorbed on oxidized and reduced anatase." J. Phys. Chem. 86 (1982): 4708-14.

41. Bickley, R. I. "Some experimental investigations of photosorption phenomena at the 
gas-solid interface." Photoelectrochemistry, Photocatalysis and Photoreactors, 491-502. M. Schiavello. NATO ASI Series C, 146. Boston: Reidel Publishing Cò., 1985.

42. Herrmann, J. M., Courbon, H., Disdier, J., Mozzanega, M. N., and Pichat, P. "Photocatalytic oxidations at room temperature in various media." New Developments in Selective Oxidation, 675-82. G. Centi, and F. Trifiro, Amsterdam: Elsevier Science Publishers B. V., 1990.

43. Al-Ekabi, H., Draper, A. M., and De Mayo, P. "Carbon tetrabromide as an electron acceptor in heterogeneous photocatalysis." Can. J. Chem. 67, no. 6 (1989): 1061-4.

44. Kutsuna, S., Ibusuki, A., and Takeuchi, H. Catalysts for disproportionation and decomposition of chlorofluoromethanes. In Japanese Patent 01,224,337. (7 September 1989).

45. Kutsuna, S., Takeuchi, K., and Ibusuki, T. "Adsorption and reaction of trichlorofluoromethane on various particles." J. of Atmos. Chem. 14 (1992): 1-10.

46. Nomichi, S., and Fujii, T. Treatment of chlorofluorocarbons. In Jpn. Kokai Tokkyo Koho P. Japan Patent 01143630 A2. Japan Patent 87-297832, 27 Nov 1987. (6 June 1989).

47. Roderwald, P. G. Method of removing chlorofluorocarbons from the atmosphere. U.S. Patent 4,997,632. 529,997, 29 May 1990. (5 March 1991).

48. Sabin, F., Turk, T., and Vogler, A. "Photooxidation of organic compounds in the presence of titanium dioxide: determination of the efficiency." J. Photochem. Photobiol. A: Chem. 63, no. 1 (1992): 99-106.

49. Daroux, M., Klvana, D., Duran, M., and Bideau, M. "Photocatalytic Oxidation of Ethane over $\mathrm{TiO}_{2}$." Can. J. Chem. Eng. 63 (1985): 668-73.

50. Anpo, M., and Tomonari, M. "Photocatalytic reactions on platinum-loaded and unloaded semiconducting materials. Differences in photoreactivities between titanium dioxide and zinc oxide." Denki Kagaku oyobi Kogyo Butsuri Kagaku 57, no. 12 (1989): 1219-20.

51. Childs, L. P., and Ollis, D. F. "Photoassisted heterogeneous catalysis: rate equations for oxidation of 2-methyl-2-butanol and isobutane." J. Catal. 67, no. 1 (1981): 35-48.

52. Al-Ekabi, H., Safarzadeh-Amiri, A., Sifton, W.; and Story, J. "Advanced technology for water purification by heterogeneous photocatalysis." Int. J. Environ. Technol. Policy Research.

53. Isidorov, V. A., Klokova, E. M., and Zgonnik, P. V. "Photocatalytic oxidation of isoprene and terpenes on the surface of the components of natural aerosols." Vestn. Leningr. Univ., Ser. 4: Fiz., Khim., no. 3 (1990): 61-6.

54. Kawashimi, M., Naka, R., Tsunoda, T., Suenaga, N., Ogawa, S., Kashiwabuchi, M., Kameda, M., and Tanaka, K. Apparatus for Removing Stink. U.S. Patent 4,954,465. (4 September 1990).

55. Sato, S. "Photo-Kolbe Reaction at Gas-Solid Interfaces." J. Phys. Chem. 87 (1983)3531-3537. 


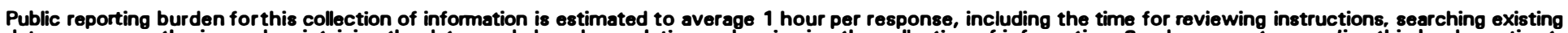

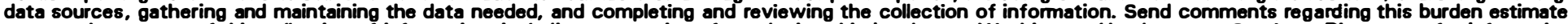

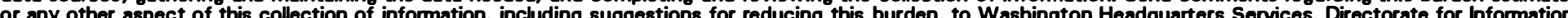

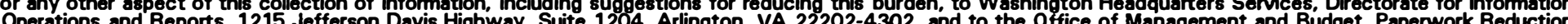
Project (0704-0188), Washington, DC 20503.

\begin{tabular}{|l|l|l} 
1. AGENCY USE ONLY (Leave blank) & $\begin{array}{c}\text { 2. REPORT DATE } \\
\text { January } 1995\end{array}$ & $\begin{array}{l}\text { 3. REPORT TYPE AND DATES COVERED } \\
\text { Technical Report }\end{array}$ \\
\hline
\end{tabular}

4. TITLE AND SUBTITLE

Review of Research Results for the Photocatalytic Oxidation of Hazardous Wastes in Air

\section{AUTHOR(S)}

Mark R. Nimlos, Edward J. Wolfrum, David A. Gratson, Andrew S. Watt, and Craig Turchi
5. FUNDING NUMBERS

(C)

(TA) $\mathbf{S 1 5 1 . 3 0 5 0}$
7. PERFORMING ORGANIZATION NAME(S) AND ADDRESS(ES)

\section{SPONSORING/MONITORING AGENCY NAME(S) AND ADDRESS(ES)}

National Renewable Energy Laboratory

1617 Cole Boulevard

Golden, CO 80401-3393
8. PERFORMING ORGANIZATION REPORT NUMBER

DE95004004

10. SPONSORING/MONITORING AGENCY REPORT NUMBER

NRELTTP-433-6943

\section{SUPPLEMENTARY NOTES}

\section{2a. DISTRIBUTION/AVAILABILITY STATEMENT}

National Technical Information Service

U.S. Department of Commerce

5285 Port Royal Road

Springfield, VA 22161 12b. DISTRIBUTION CODE

UC-1303

\section{ABSTRACT (Maximum 200 words)}

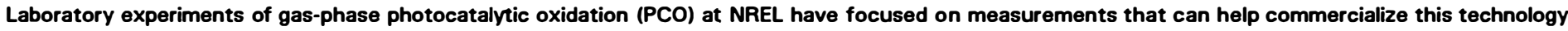

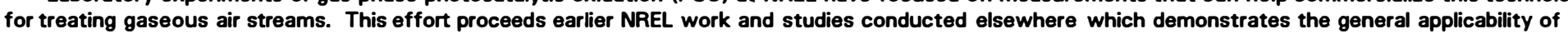

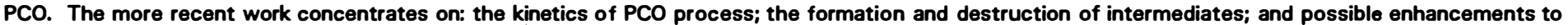
improve the destruction rates.
14. SURUECT TERMS
15. NUMBER OF PAGES

Photocatalytic oxidation, waste destruction, laboratory studies, air pollution prevention, ethanol, trichlorethylene, benzene, BTEX

56

16. PRICE CODE

A04

20. LIMITATION OF ABSTRACT

\begin{tabular}{l|l|c}
\hline 17. SECURITY CLASSIFICATION & $\begin{array}{c}\text { 18. SECURITY CLASSIFICATION } \\
\text { OF REPORT }\end{array}$ & $\begin{array}{c}\text { 19. SECURITY CLASSIFICATION } \\
\text { OF ABSTRACT PAGE } \\
\text { Onclassified }\end{array}$
\end{tabular}
Unclassified OF THIS PAGE

Standard Form 298 (Rev. 2-89) Prescribed by ANSIStd. Z39.18 